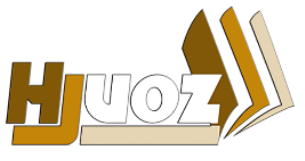

hjuoz.uoz.edu.krd p-ISSN: $2410-7557$
كَوّارا زانستيّن مروّقايهتى يا زانكوّيا زاخوّ

مجلة العلوم الانسانية لجامعة زاخو

Humanities Journal of University of Zakho (HJUOZ)

Vol. 4, No. 3, pp. 693-706, December-2016

موقف الإتحاد السوفيتي من القضية الكُردية 1970 - 1974في ضوء جريدة التآخي

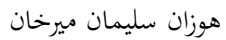 \\ قسم التاريخ، كلية العلوم الإنسانية، جامعة دهوك، إقليم كُردستان - العراق.
}

\title{
https://doi.org/10.26436/2016.4.3.304
}

الخلاصة: - n

يتناول هذا البحث موقف الإتحاد السوفيتي من القضية الكُردية 1970 - 1974 في ضوء جريدة التآخي، التي كانت لسان

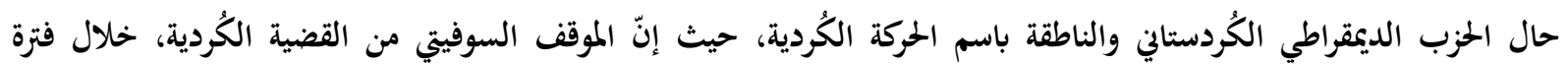

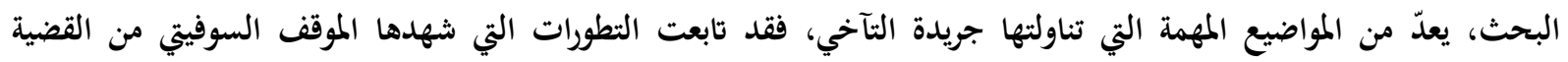

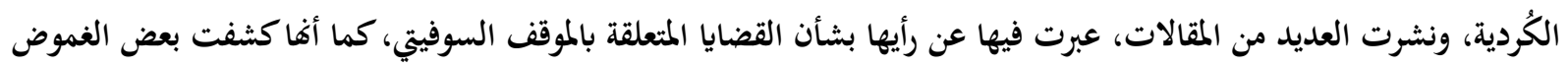

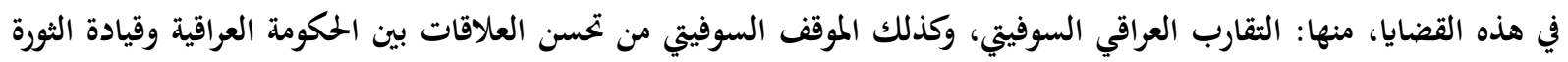
الكُردية والذي توج بإعلان بيان 11 آذار الفيالي منها: 1970، فضلاً عن معاهدة الصداقة عام 1972 بين الحكومة العراقية والإتحاد السوفيتي،

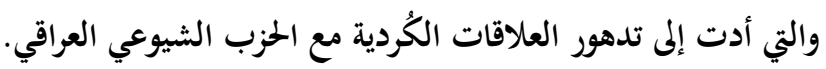

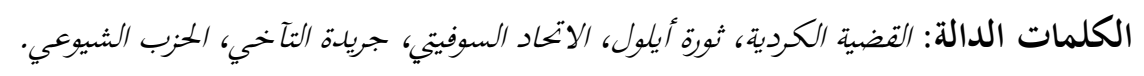

إتفاقية في موسكو في 21 حزيران 1969 حول تأمين المعونة

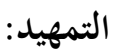

الفنية السوفيتية، التي أدت إلى زيادة مؤيدي السوفيت في في

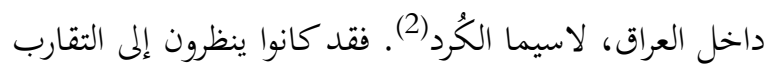

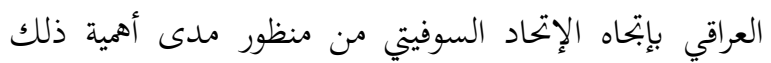

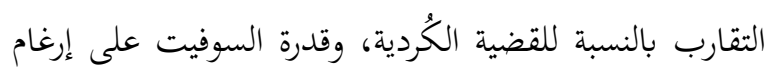

العراق لتلبية مطاليبهم (3). ومن الملاحظ أنّ الإتحاد السوفيتي في سياسته بتحاه القضية

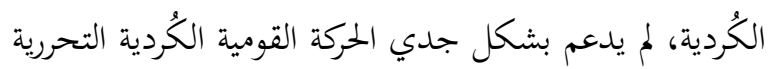
وقيادتها بالتوجه نحو القتال ضد الحكومات العراقية حتى انه لم لم يدعُ صراحة إلى الحلول العسكرية لهذه القضية، بل إنه كان

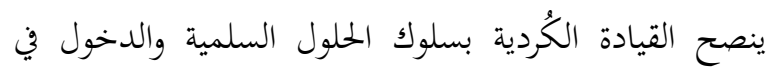

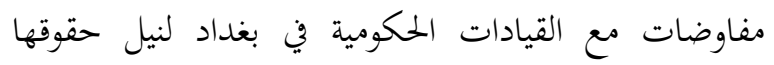
القومية، ومن الظاهر أن هذا الإبحاه قد ولد لدى الساسة السوفيت في ظل سياستهم العامة بعدم إشعال حروب أهلية

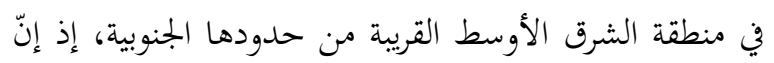

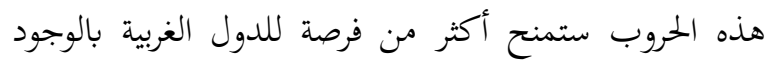

حاولت الحكومات العراقية المتعاقبة ولاسيما في العهد

الجمهوري (1958 - 1968)، إيجاد نوع من التوازن في علاقاتا بين المعسكر الاشتراكي بقيادة الإتحاد السوفيتي

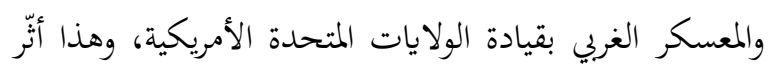
بصورة غير مباشرة على سياسة الإتحاد السوفيتي تحاه الحركة

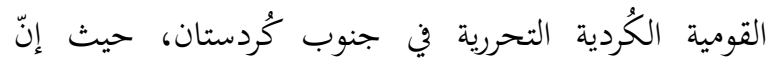

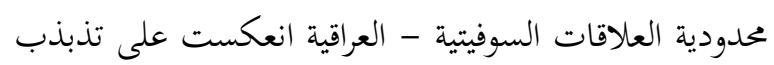

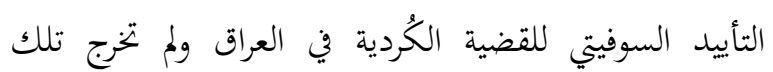
العلاقة من هذا الإطار على الرغم من تعاطفه المعنوي بتحاه قضية الشعب الكُردي(1). شهدت العلاقات العراقية - السوفيتية تقارباً واضحاً في الخردي أواخر الستينات ومطلع السبعينات من القرن العشرين، فقد

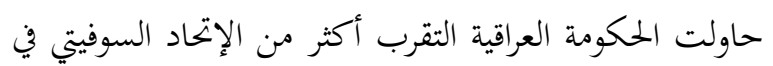

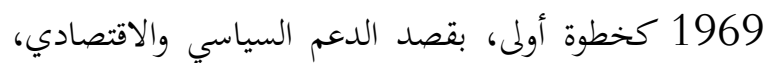
الذي يمكن أن يقدمه الإتحاد السوفيتي للعراق، فاستأنفت التهدي المفاوضات مع الحكومة السوفيتية والتي توجت بالتوقيع على لئي 
1970 يتفق والمصالح الجذرية للشعب العراقي ويخدم قضية تعزيز الاستقلال الوطني ووحدة الجمهورية العراقية والديمقراطية

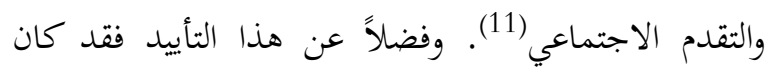

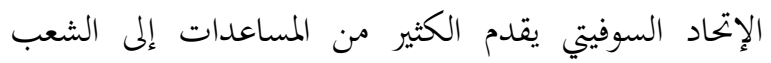

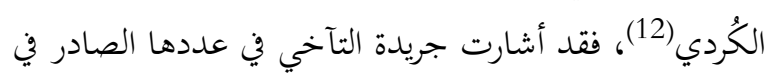
14 كانون الثاني 1971 إلى وصول الباخرة السوفيتية أوديسكي كومسومولتيس إلى ميناء البصرة وهي تحمل شحنة من المساعدات السوفيتية للشعب الكُردي أرسلتها جمعية

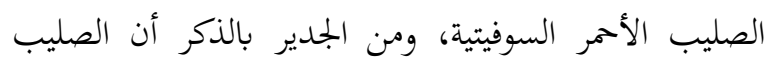

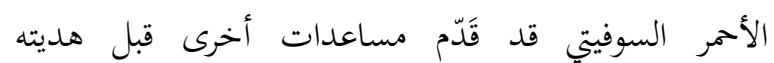
الأخيرة(13). أستمرت جريدة التآخي بنشر مواقف الدوائر السوفيتية من إعلان بيان الحادي عشر من آذار، فني الذكرى السنوية

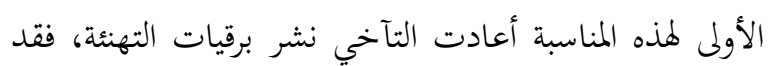

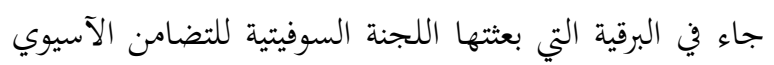

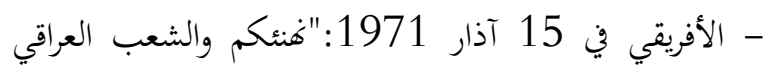
قاطبة بالذكرى السنوية لإتفاقية 11 آذار. إن مساهمة مثثلين

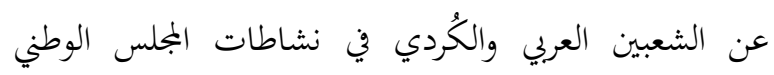
للسلم والتضامن هي تطبيق لمبادىء هذه الإتفاقية التاريخية

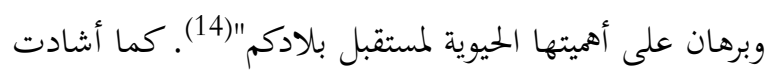
التآخي في عددها الصادر في 27 تشرين الأول 1971

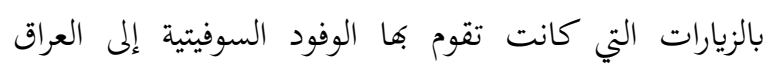

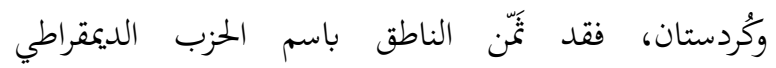

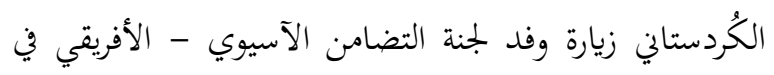
الإتحاد السوفيتي، وأعتبرها خطوة في طريق توطيد الصداقة

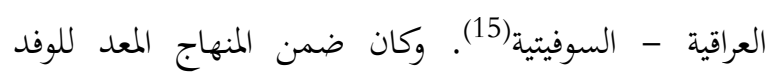

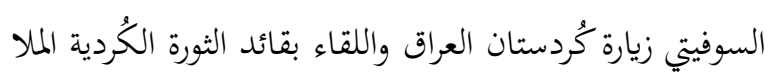

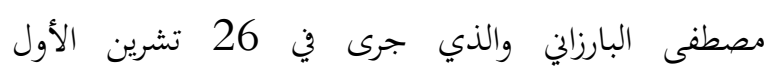

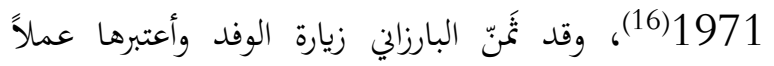

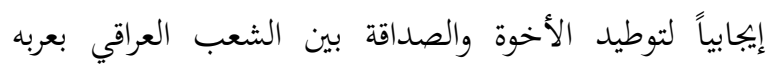

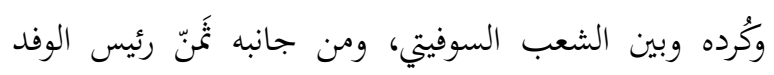

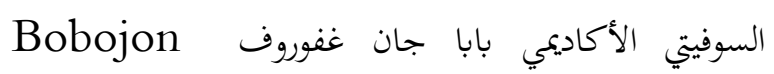
Ghafurov
قرب الحدود السوفيتية وبهذا ووفق حسابات السوفيت سيؤدي إلى تمديد السلام العالمي (4).

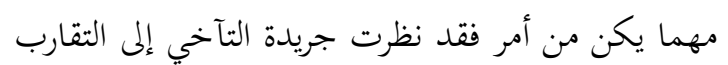

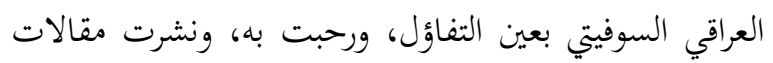

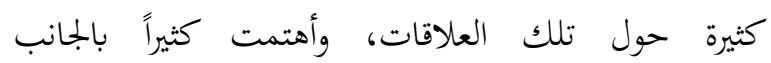

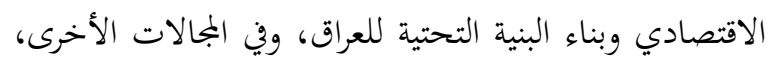

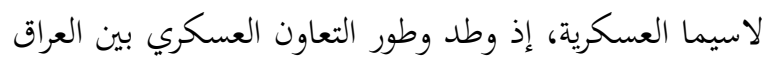
والإتحاد السوفيتي (5). أولاً: سياسة الإتحاد السوفيتي تجاه الحركة الكُردية 1970 $-: 1972$ عندما توصلت الحلكومة العراقية، وقيادة الثورة الكُردية إلى

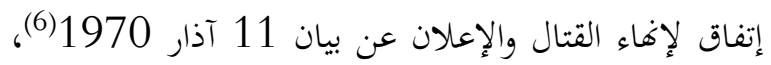

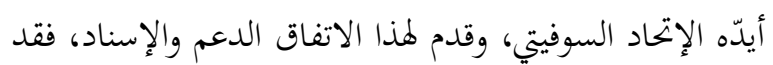
شارك السوفيت في المفاوضات التي جرت بين قيادة الثورة

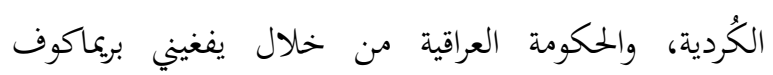
(7) Yevgeny Primakov السوفيتية. فكان الإتحاد السوفيتي ينصح العراق، وقيادة الثورة

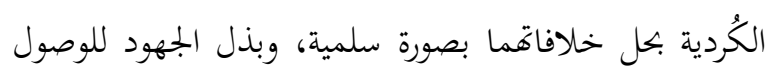

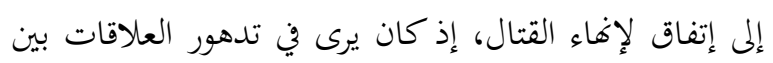

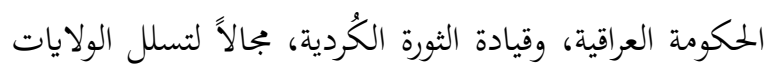

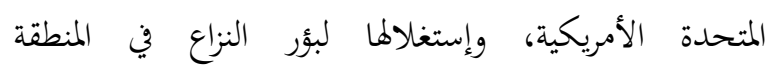

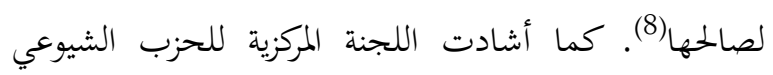

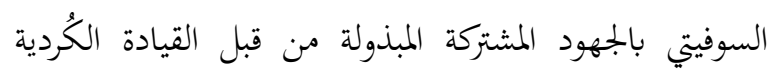

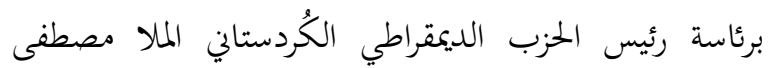
البارزاين (1903 - 1979) وحكومة العراق والتي أدت

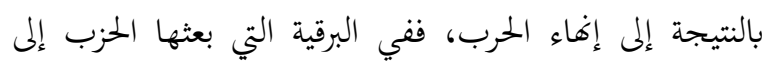

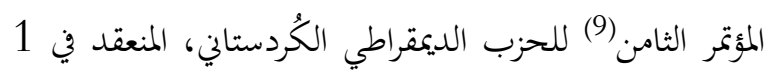

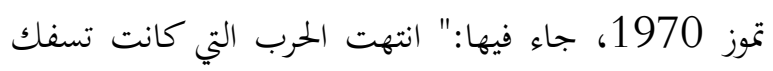

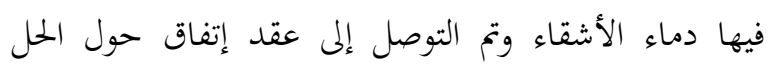
السلمي للقضية الكُردية. إنّ شعبي الجمهورية العراقية عرباً التهاء وأكراداً يملكان كافة الظروف للحياة السلمية البناءة ويوطدان

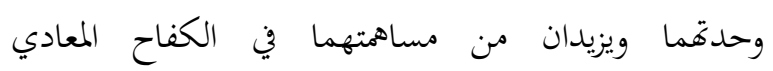
للإستعمار"(10). وأضافت البرقية إلى أن بيان 11 آذار 
إتحاد نساء كُردستان. كما وعدت الأخوة السوفيتيات بتوجيه ارساليات باسم إتحاد نساء كُردستان تحتوي على دفاتر وأقلام

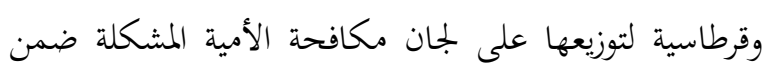

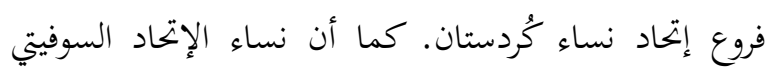

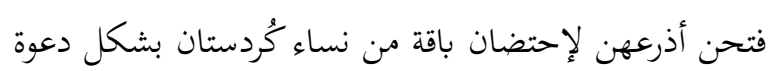

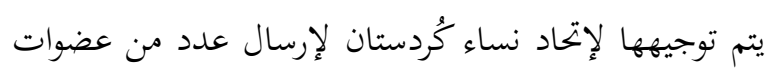

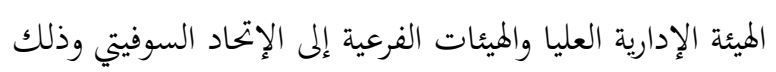

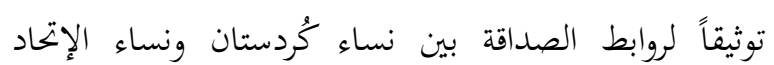
السوفيتي (21).

وتعزيزاً لروح الصداقة الكُردية - السوفيتية، أقام المركز

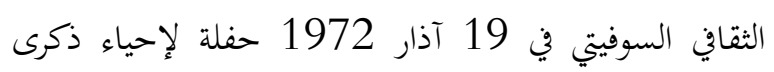
بيان 11 آذار وأعياد نوروز حضره أعضاء المكتب السياسي

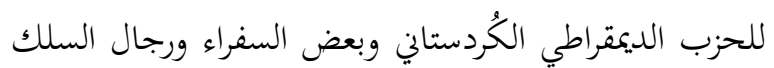

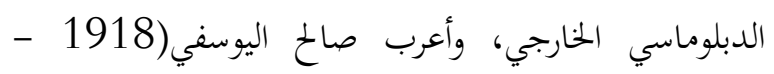

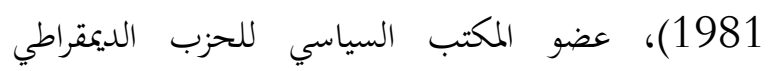
الكُردستاني، عن شكره وتقديره لهذه الإلتفاتة الطيبة من المركز الثقافي السوفيتي ومشاركته مع الشعب الكُردي في تخليد هاتين المناسبتين السعيدتين والتي تنطوي على الصداقة المبدئية المتينة بين الشعبين الكُردي والسوفيتي (22). تولت جريدة التآخي نقل التصريحات والخطب للمسؤولين السوفيت والتي تؤكد على توثيق العلاقات بين الإتحاد السوفيتي وقيادة الثورة الكُردية، فقد دعا اليكسي كوسيجين Alexei - 1964 رئيس وزراء الإتحاد السوفيتي (196yin

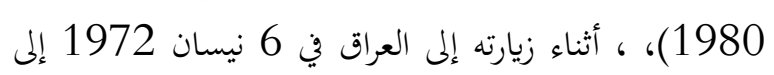
تعميق تنفيذ بيان الحادي عشر من آذار وإقامة جبهة القوى إنى

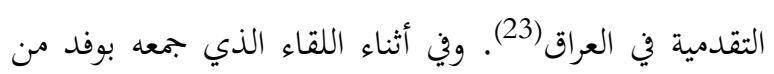

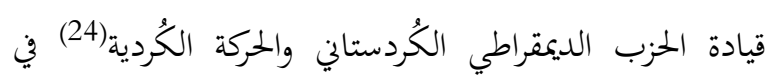

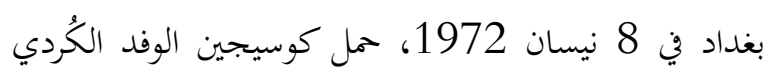
1964) Leonid Brezhnev تحيات ليونيد بريجنيف - 1982)، سكرتير اللجنة المركزية للحزب الشيوعي لئيل

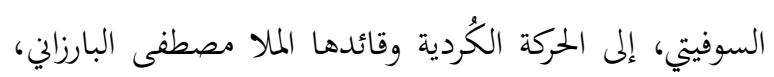

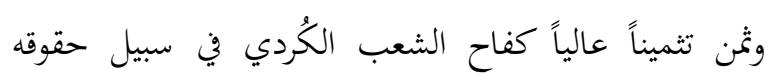

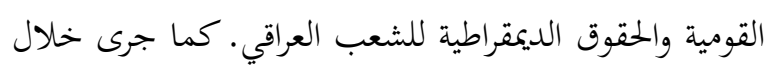

العلوم السوفيتية، بيان آذار باعتباره إنتصاراً عظيماً للشعب العراقي بصورة عامة وللشعب الكُردي بصورة خاصة، فلأول الكال

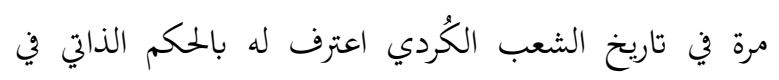
إطار الجمهورية العراقية. وأضاف رئيس الوفد السوفيخ السوفيتي

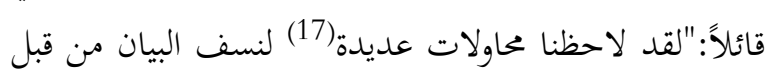

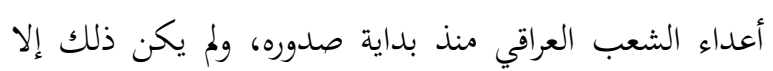
بسبب الأهمية التي يتمتع بها البيان لمستقبل تطور الحركة

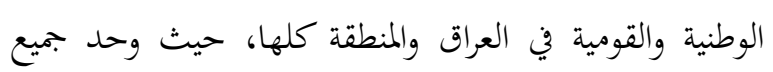

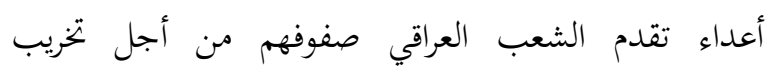
البيان" (18) يبدو أن تحسن العلاقات الكُردية - السوفيتية قد البدان أنعكست آثاره على جميع شرائح المجتمع الكُردي، ففي 29

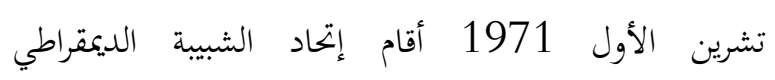

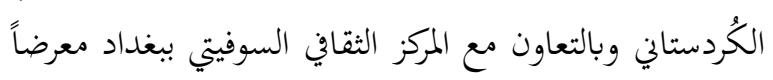

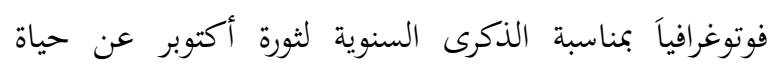

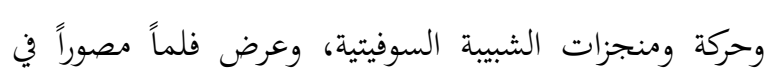
مقر الشبيبة الكُردستاني عن الحركة النشطة للشبيبة السوفيتية

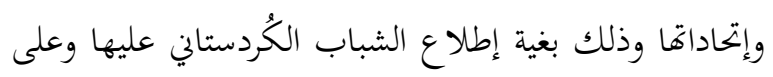
معالم النهضة الشاملة في كل الحقول والفروع في الإتحاد السوفيتي (19). وفي سياق تنشيط التعاون بين المنظمات الجماهيرية الكُردية - السوفيتية، جرت لقاءات وزيارات عديدة بين إتحاد نساء كُردستان ولجنة النساء السوفيتيات في كانون الأول 1971، عبرت فيها الأخوة السوفيتيات وبالدعم المادي والمعنوي عن تضامنهن وتقديرهن للمسؤولية التي ينهض بها وبها إتحاد نساء كُردستان في عهد السلام والوحدة الوطنية لترميم التصدعات والمشاكل الثقيلة التي أصابت الأسرة الكُردستانية

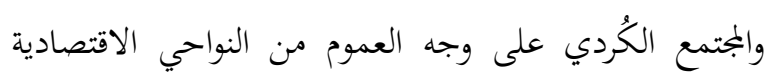

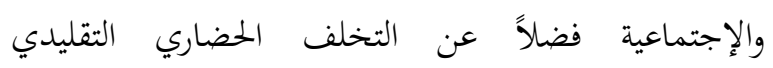

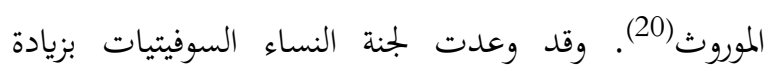

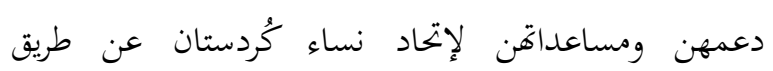
تخصيص مقعدين لنساء كُردستان في الجامعات السوفيتية بشكل دائمي سنوياً على أن يتم ترشيحهن وتزكيتهن من قبل فرديل 
وعلى الرغم من هذه النظرة التفاؤولية لدى جريدة التآخي

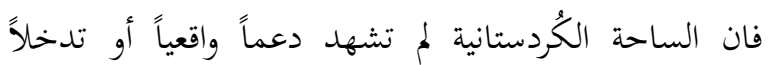

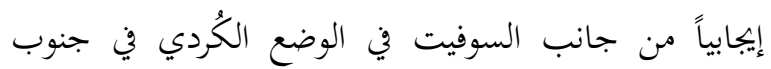
كُردستان.

ثانياً: الموقف الكُردي من تطور العلاقات العراقية السوفيتية 1970 - 1972:في عام 1970 جرت مفاوضات في موسكو بين الحكومة

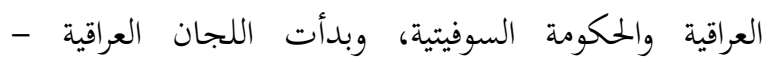

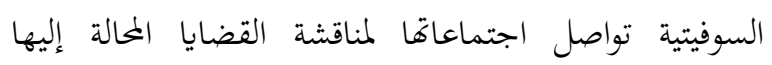

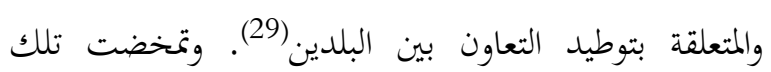
المباحثات عن البروتوكول الصادر في 14 آب 1970 للتبادل التجاري، وتطوير العلاقات بصورة أوسع بين البلدين(30).

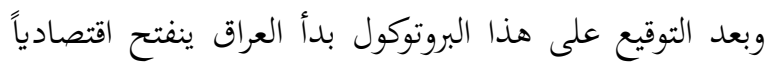

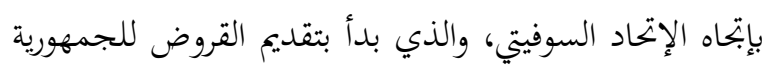

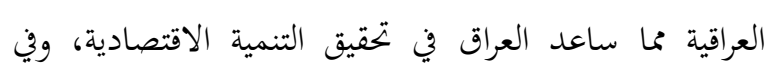
إنشاء عدد من المشاريع الصناعية(31). رحبت جريدة التآخي بالتعاون بين الحكومتين العراقية

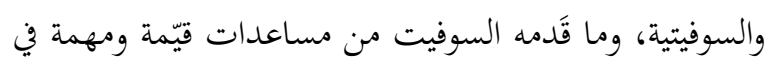

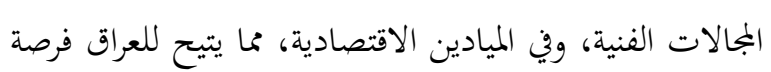

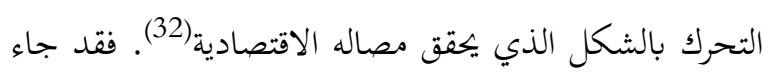

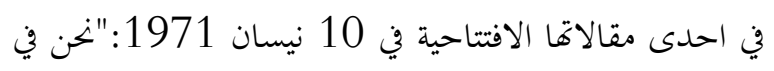
الوقت الذي نؤيد ونبارك كل خطوة على طريق تصنيع بلادنا

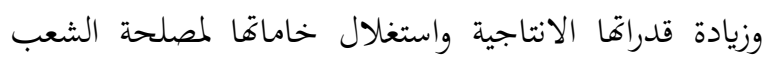

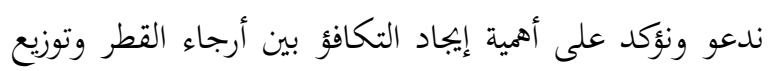

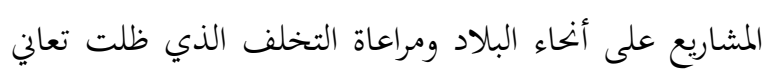

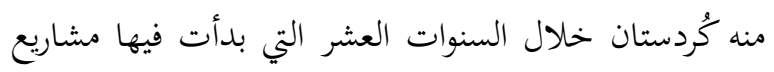
معاهدة التعاون الاقتصادي والفني مع الإتحاد السوفيتي تأتي

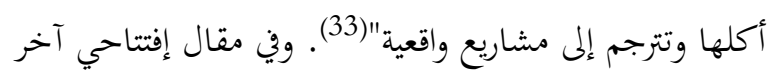

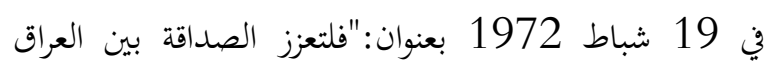

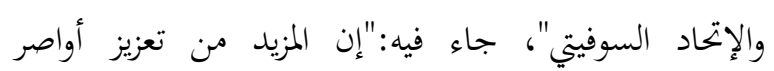
الصداقة مع البلدان الاشتراكية وفي مقدمتها الإتحاد السوفيتي
اللقاء تأكيد مشترك على أهمية تنفيذ بيان الحادي عشر من آذار وتكوين الجبهة الوطنية وتطوير علاقات الصداقة بين الإتحاد السوفيتي والجمهورية العراقية(25). وتابعت التآخي تفاصيل زيارة الوفد السوفيتي إلى العراق، ففي عددها الصادر في 6 نيسان 1972 نشرت مقالاً افتتاحياً بعنوان:"أهلاً بضيف العراق الكبير"، رهُب فيه بالوفد

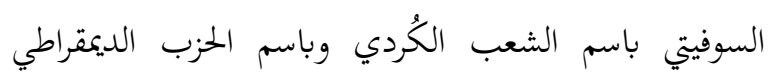

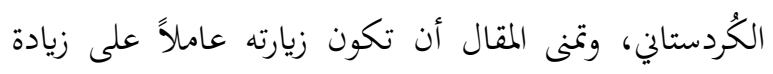
تعزيز علاقات الصداقة بين العراق والإتحاد السوفيتي لما فيه خير البلدين ودعم الحركتين القوميتين التحرريتين العربية

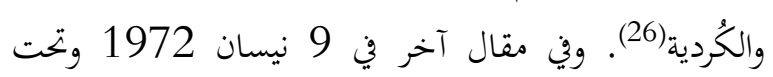

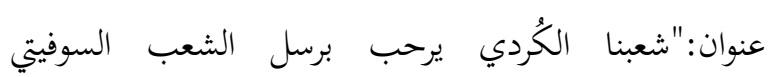

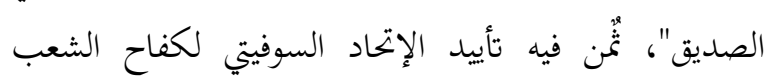

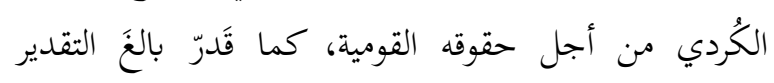

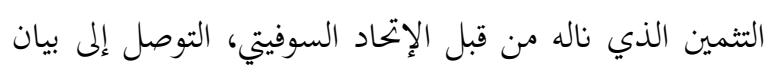

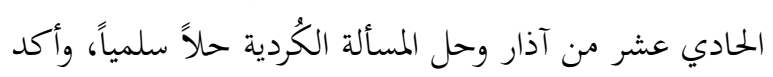

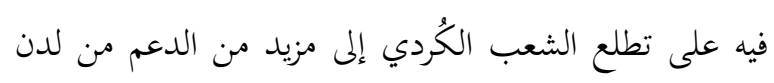

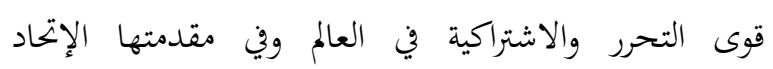
السوفيتي (27). وهكذا أخذت العلاقات بين قيادة الثورة الكُردية وبين الإتحاد السوفيتي تتوثق على جميع المستويات، ففي 14 نيسان

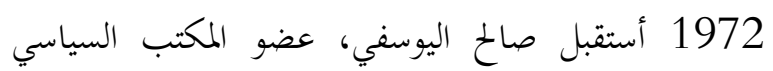

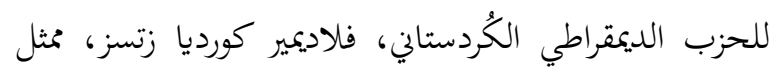

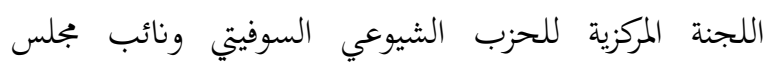

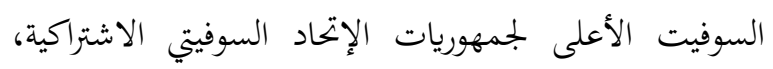
وجرت المحادثات حول القضية الكُردية ومسيرة بيان الحادي الإداد السوفيتي الثراكية عشر من آذار والجبهة الوطنية وأهمية توطيد العلاقات بين

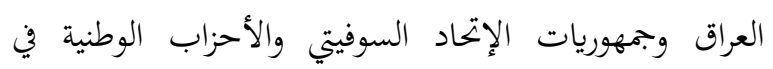

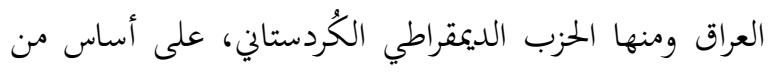
الصداقة المتينة والأحترام المتبادل والمصالح والتطلعات المشتركة. وقد أبدى رئيس الوفد السوفيتي رغبته في زيارة كُردستان واللقاء برئيس الحزب الملا مصطفى البارزاني (28). 
خاصة(37). ويبدو أن هذا الأمل والتفاؤل قد جاء نتجيةً للموقف السوفيتي المؤيد لبيان 11 آذار 1970. شهات العلاقات الاقتصادية العراقية - السوفيتية تطوراً

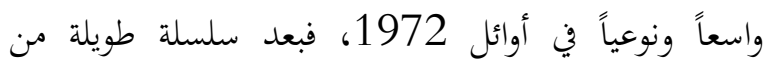
المباحثات والمفوضات توصل الجانبان العراقي والسوفيتي إلى ولى

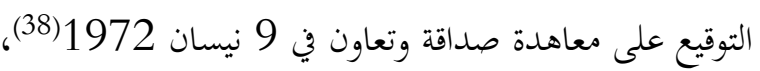
والتي نصت على التعاون الكامل في مختلف الحقول السياسية والاقتصادية والتجارية والثقافية والدفاعية، وعلى أساس المنافع المتبادلة للطرفين(39). وتابعت التآخي تلك المعاهدة، وعلقت عليها في مقالاتما الإفتتاحية، فقد نشرت مقالاً إفتتاحياً في 12 نيسان

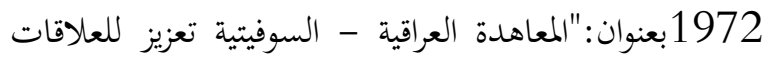
القائمة بين البلدين"، جاء فيه:"لقد جاء توقيع هذه المعاهدة

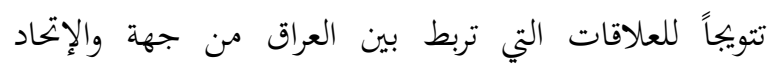

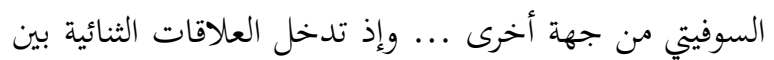
البلدين مرحلة جديدة، تؤدي بالضرورة إلى تطور شامل في العلاقات في جميع الميادين، وتترك أثرها على أوضاع البلاد العامة ومسارها وعلى العلاقة بين الشعبين السوفيتي والعراقي

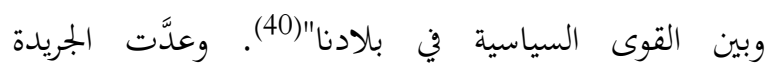

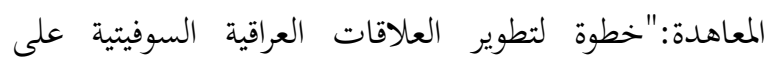

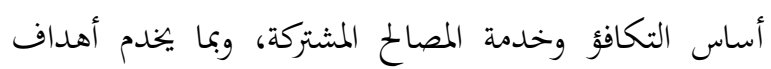
الشعب العراقي بعربه وكُرده في تحقيق أمانيه المشروعة وإنجاز

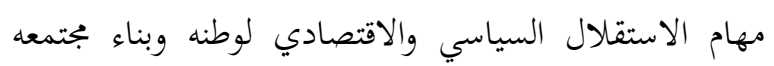
المتطور وتحقيق المساواة القومية"(41). وهكذا أهتمت التآخي بتلك المعاهدة، واعتبرتحا ركناً أساسياً في إزدهار وتطور الصداقة العراقية - السوفيتية، ولكن في الوقت نفسه أشارت على أنه يجب أن تُدركَكَ أهمية الدور

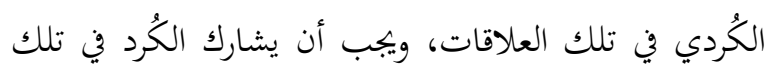

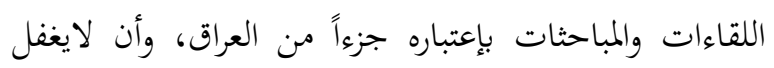

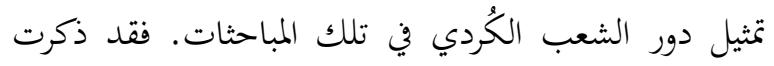
هذذا الخصوص في 12 نيسان 1972:"إن حزبنا الديمقراطي الكُردستاني لايسعه في معرض التوقيع على معاهدة الصداقة

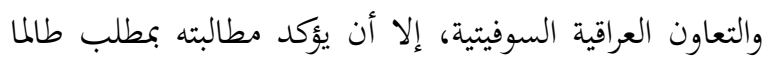

ومع الحركة التقدمية في العالم، ضمانة أساسية لصيانة استقلالنا وتعزيز دعائم حريتنا"(34). ويبدو من ذلك أن التآخي شددت بضرورئ دريتنات أن تأخذ كُردستان نصيبها من تلك المفاوضات والاتفاقيات المعقودة بين العراق والإتحاد السوفيتي، ويجب أن يكون على أساس

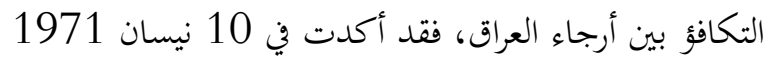
بالقول:"إذا كان الإتحاد السوفيتي الصديق وفياً في تعهداته واتفاقاته وقيامها على أساس من تكافؤ وعلاقات المصالح المشتركة، فإننا نجد أن المشاريع المشار إليها في بروتوكول عام وعام واني

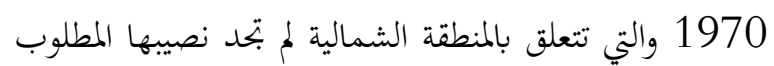
في المفاوضات التي جرت في بغداد مؤخراً إذ إنّ البروتوكول نص على الكثير من المشاريع المهمة التي قم إعمار كُردستان

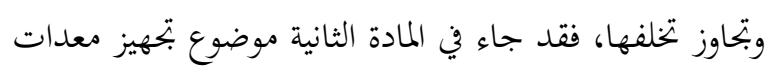
ومكائن لتطوير بعض الفروع الاقتصادية في المناطق الشمالية من العراق، وكذلك موضوع بتهيز المعدات اللازمة لحفر آبار

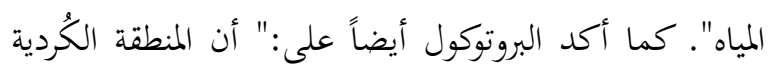
تعاني إهمالاً ولم تأخذ نصيبها من مساعدات الأصدقاء السوفيت بسبب إقدام الجانب العراقي على طلب تنفيذ جانب معين من الاتفاقية وهذا ما يدعونا إلى المطالبة بإثارة

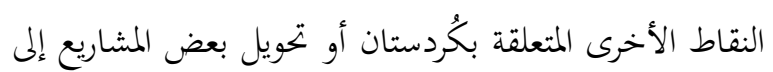

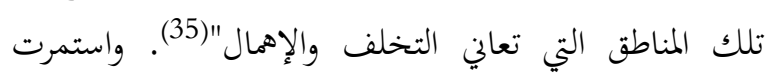

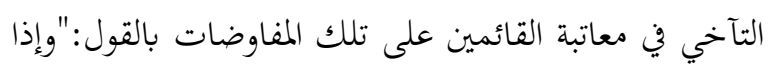
كان لنا من كلمة بهذه المناسبة فهي كلمة عتاب نوجهرابها بمناسبة إغفال تمثيل شعبنا وحزبنا في مفاوضات على هذه هذا هندا

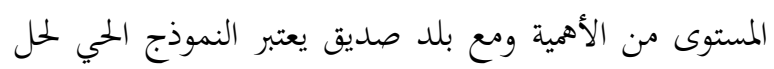

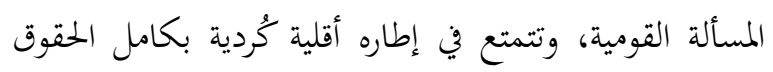
القومية. وقد وصل في ظل الحكم السوفيتي إلى أعلى درجات الرقي الذي يمكن أن تبلغه أقلية قومية"(36). وعلى الرغم من ذلك فقد شعرت التآخي بالأمل والتفاؤل

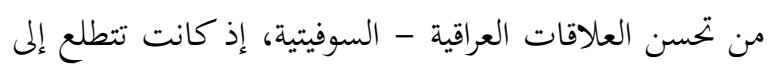
المستقبل الذي يستطيع خلاله العراق تحقيق الرفاه الاقتصادي

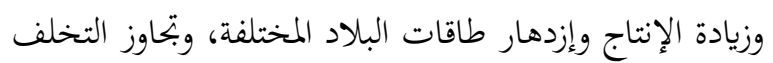

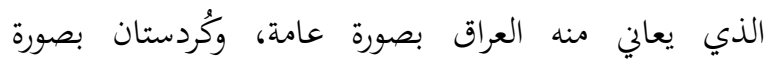


الوطنية وشعوب الإتحاد السوفيتي وحزبها الشيوعي بإعتبار

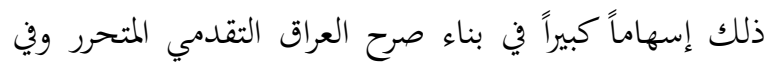
تعزيز قضية الكفاح ضد الإستعمار والرجعية"(45).

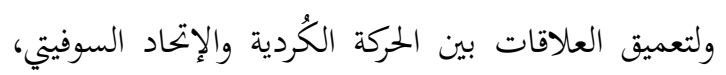

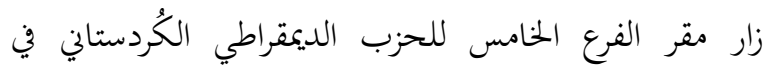

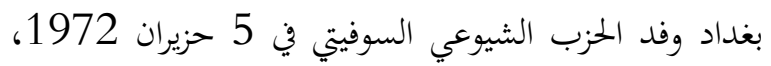

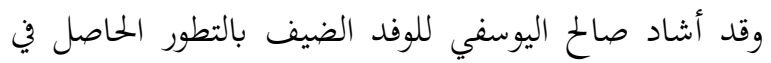
العلاقات المتبادلة بين العراق والإتحاد السوفيتي على المستويين الرسمي والشعبي وتبادل زيارات الوفود المختلفة بين البلدين،

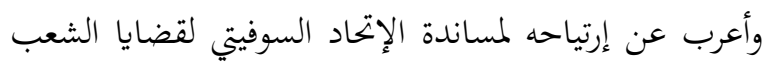

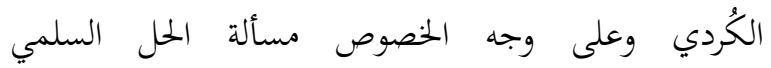

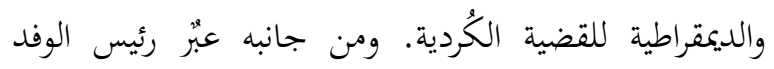
السوفيتي مالياخوف Maliakhov عن إعجابه بكفاح الشعب الكُردي العادل لنيل حقوقه القومية في إطار الجمهورية العراقية على أساس بيان الحادي عشر من آذار، وطلب إبلاغ تحيات الحزب الشيوعي السوفيتي إلى الملا مصطفى البارزاني

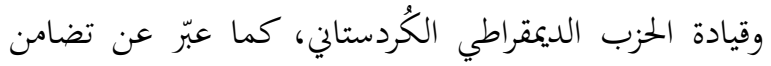
الإتحاد السوفيتي مع الشعب العراقي في كفاحه من أجل بناء

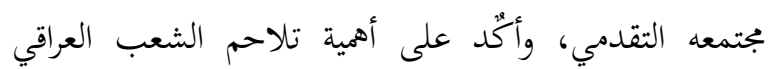
وأحزابه الوطنية وبقية القوى الوطنية(46).

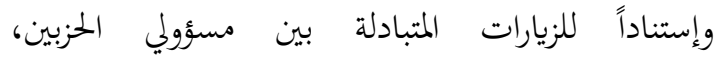
والتصريحات التي دعت إلى توسيع العلاقات بينهما، وبمناسبة

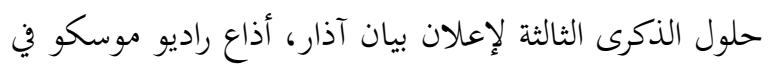

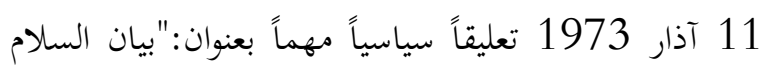
والآخاء"، جاء فيه:"مرت ثلاثة أعوام على اليوم الذي تم فيه توقيع البيان في العراق بوقف القتال بين القوات العراقية والأخوة الأكراد ذلك القتال الذي دام تسعة أعوام. وبيان

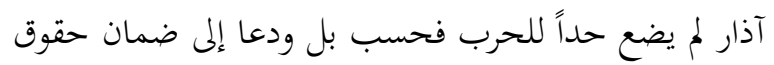

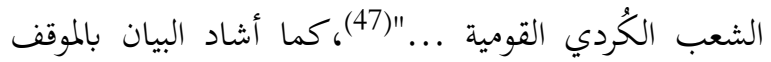

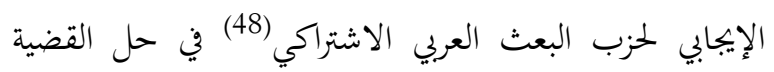

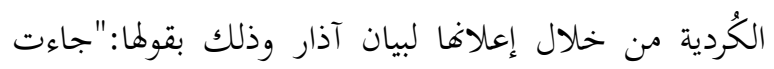

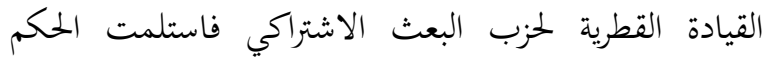
وقامت بتصحيح الأخطاء التي ارتكبتها الحكومات السابقة.
نادى به ألا وهو ضرورة مشاركته في تقرير الأمور المتعلقة

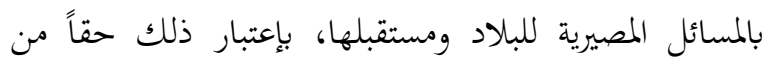
حقوقه إن لم يكن بوصفه مشاركاً في الحكومة فلتمثيله القومية

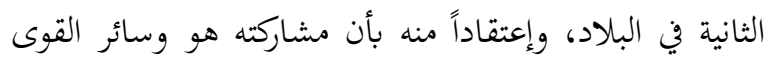

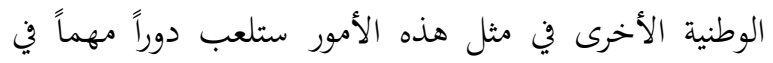
توحيد صفوف الشعب وتعزيز مواقع الحركة الوطنية والسلطة نفسها" (42). يظهر مما سبق أن جريدة التآخي سخُرت إمكانياتما الإعلامية لتبيّنَ للجانبين العراقي والسوفيتي، مدى أهمية الدور إنيق

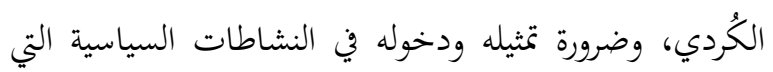

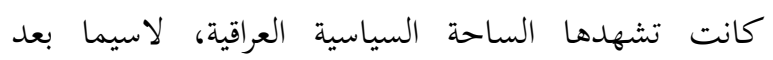
التقارب الذي حصل في العلاقات العراقية - السوفيتية. ثالثاً: المثلث (الكُردي - الحزب الثيوعي الثرات العراقي السوفيت) بعد معاهدة 9 نيسان 1972: أ - العلاقات الكُردية - السوفيتية: أستمرت التآخي في هجها المؤيد للتقارب العراقي

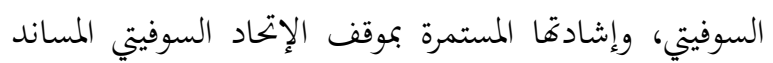

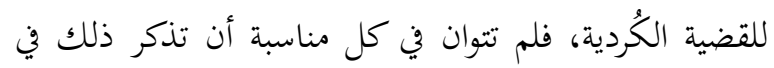
إطار تقييها للعلاقات الإيجابية بين العراق والإتحاد

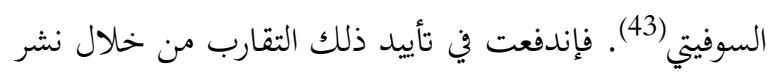
المقالات الإفتتاحية بهذا الخصوص، ففي مقال إفتتاحي في فئيل 27 آذار 1973 بعنوان:"لتزدهر الصداقة العراقية السوفيتية"، جاء فيه:"... ولا ننسى ونحن في صدد تقييم العلاقات العراقية السوفيتية أن ننوه بالتأييد المخلص الذي تئي

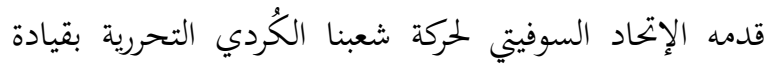
البارزاني ودورها الإيجابي في التوصل إلى إتفاقية آذار التاريخية

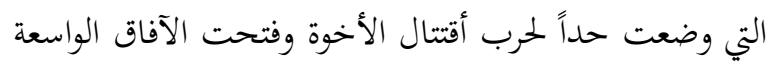

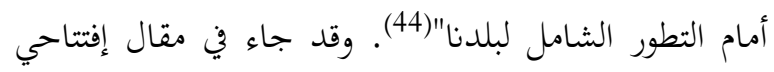
آخر في 9 نيسان 1973:".... أن الشعب الكُردي وحزبنا

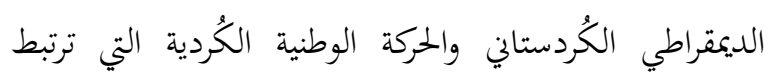
بشعوب الإتحاد السوفيتي والحزب الشيوعي في الإتحاد السوفيتي بروابط متينة، تؤكد دوماً على توطيد العلاقات الأخوية بين الجمهورية العراقية والإتحاد السوفيتي وبين الشعب العراقي وقواه 
والزيارات المتبادلة بين مسؤولي الطرفين، ففي 17 تموز 1973 جرى لقاء ودي في بغداد بين الحزب الشيوعي السوفيتي والحزب الديمقراطي الكُردستاني، حيا فيه رئيس الوفد السوفيتي

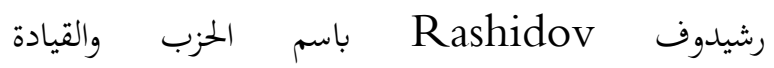
السوفيتية:"مصطفى البارزاني قائد الشعب الكُردي وقيادة

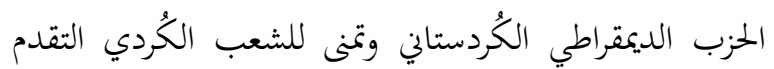

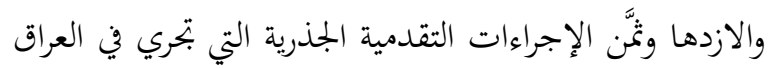

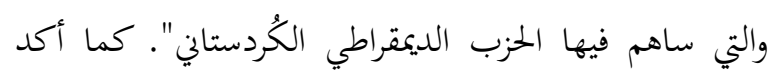

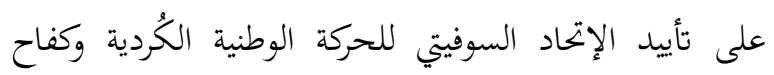

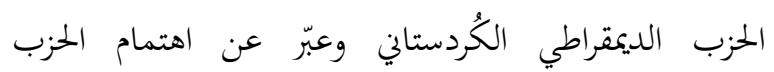
الشيوعي السوفيتي بتطوير العلاقات مع الحزب الديمقراطي

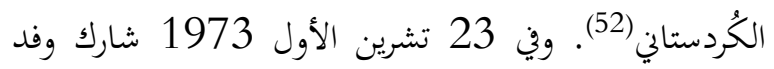
من الحزب الديمقراطي الكُردستاني، ضمن وفد المجلس الوطني لأنسي

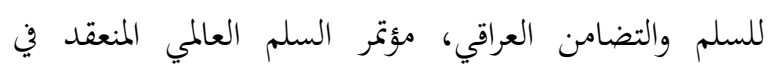

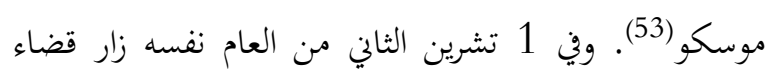

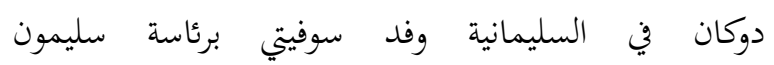
سكاتشوف Sulaimon Skatshov رئيس لجنة الدولة للعلاقات الاقتصادية الخارجية لمجلس الوزراء السوفيتي واطلع

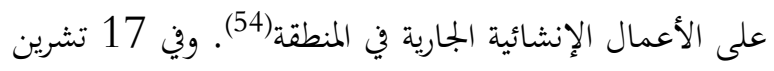

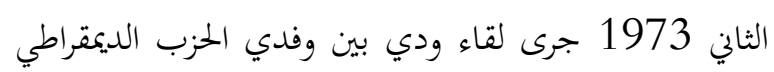

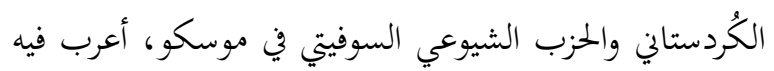

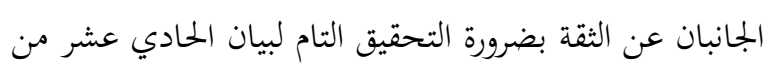
آذار، وكذلك العمل على تطوير علاقات الصداقة والتعاون

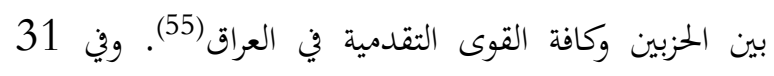
تشرين الثاني 1973 جرى لقاء آخر في بغداد بين وفد الثداف الحزب الشيوعي السوفيتي والحزب الديمقراطي الكُردستاني، أشاد الجانبان فيه بتطوير العلاقات بين العراق والإتحاد العزي السوفيتي وبين الشعب السوفيتي والشعب العراقي بعربه وكُرده،

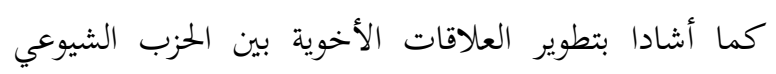

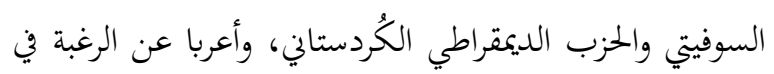
تطوير هذه العلاقات(56).

ويرجع هذا التقدم الواضح في العلاقات الكُردية السوفيتية خلال ذلك العام إلى جملة أسباب لعل من أبرزها
وفتح بجيئها هذا إلى الحكم الطريق لحل قضية الأكراد وتنفيذ تدابير عظيمة لتصفية آثار الماضي الإستعماري في العراق، ومن المعروف أن القرار التاريخي بتأميم شركة نفط العراق في الإنماري

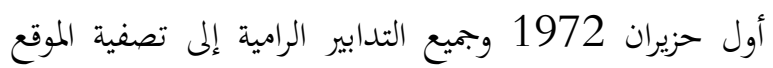

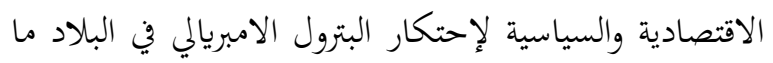

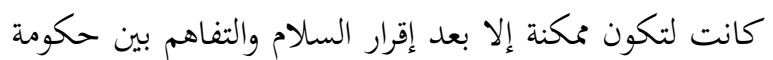
الرئيس أحمد حسن البكر [1968 - 1979] وقيادة حركة التحرر الكُردية للملا مصطفى البارزاني"(49).

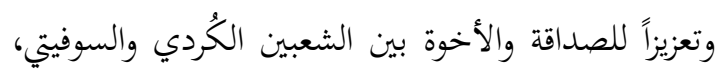
أقام المركز الثقافي السوفيتي في بغداد في 18 آذار 1973 1973،

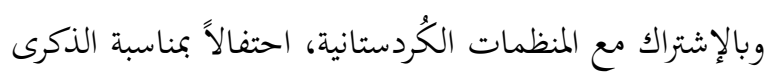

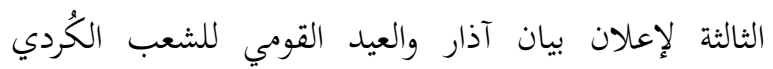
نوروز، ألقى صالح اليوسفي كلمة في الاحتفال حيا فيها:"ثورة

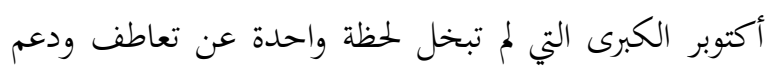

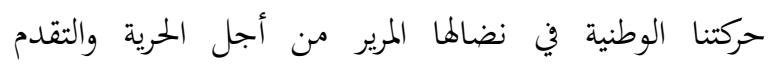

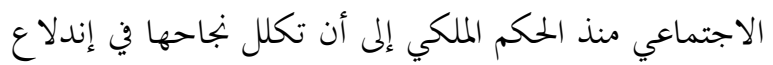

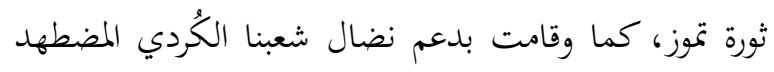

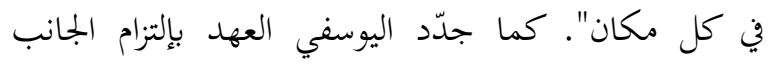

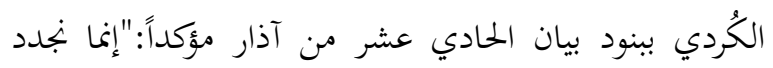

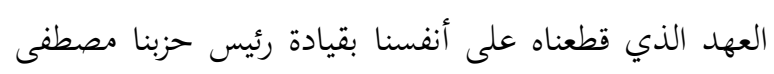

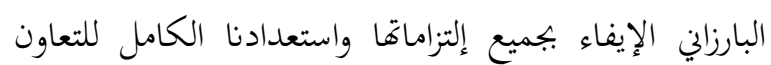
الصادق مع كل الأحزاب الوطنية والصديقة من أجل ضمان إنمان

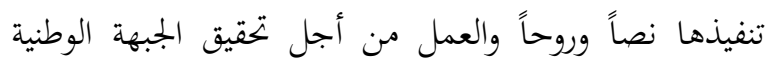

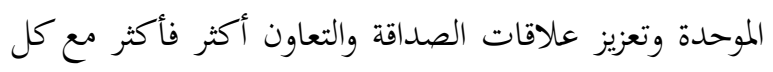
الشعوب وفي مقدمتها شعوب منظومة الدول الاشتراكية والإتحاد السوفيتي"(50). ويبدو أن الاحتفال بإحياء الذكرى السنوية لإعلان بيان

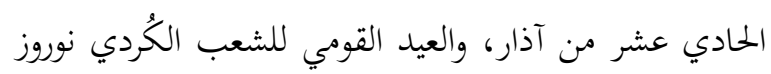

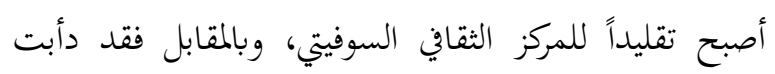
جريدة التآخي إلى إحياء الذكرى السنوية لثورة أكتوبر الاشتراكية(51).

بدأت العلاقات الكُردية - السوفيتية تشهد نشاطاً ملحوظاً في عام 1973، عبرت عنها بجموعة من التصريحات 
السوفيتي بعد قطع العلاقة بينهم وبين قيادة الحزب الديمقراطي الكُردستاني (62). كان من نتائج هذا التحول في موقف الحزب الشيوعي

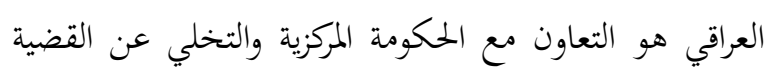

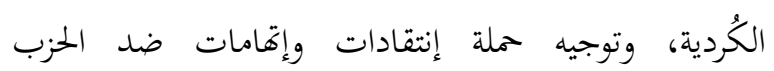

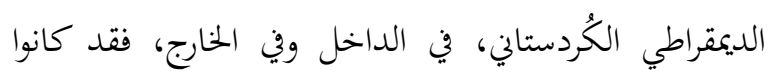

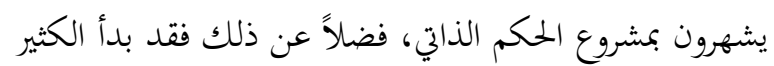
من أنصار الحزب الشيوعي الذين حاربوا الأنظمة العراقية

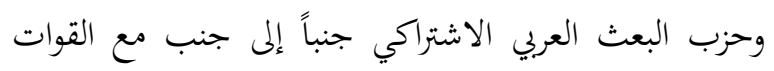

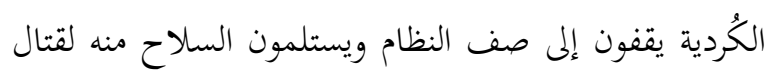
قوات الثورة الكُردية(63). وبعد ذلك نشبت معركة قلمية بين الصحيفتين: التآخي،

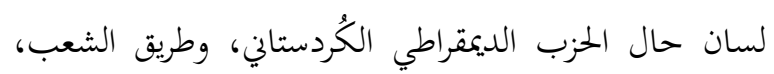

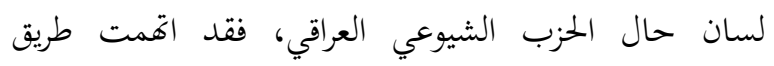

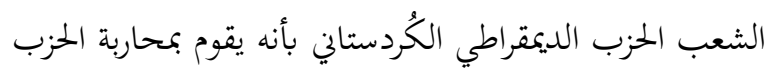

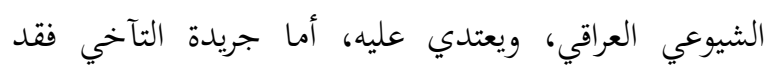

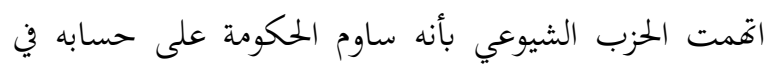
توقيعه على ميثاق الجبهة الوطنية(64). أستمرت الاتمامات المتبادلة بين الصحيفتين، فقد أشارت أنسات طريق الشعب إلى وجود حملة عسكرية ضد الشيوعيين وأنصارهم، وبدأ الحزب الشيوعي ينظم وفوداً من النساء

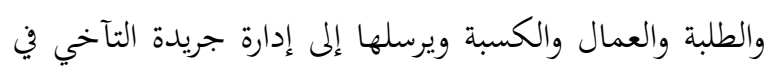

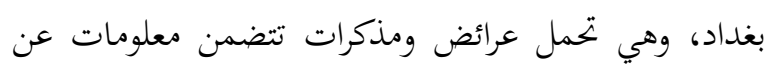
الوضع في كُردستان، حيث يجري تصوير الوضع وكأنه حملة ومائل

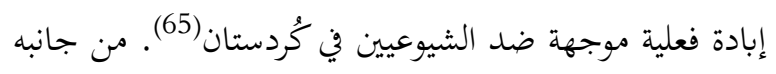
بدأت التآخي بالرد على ذلك في 13 تشرين الثاني 1973

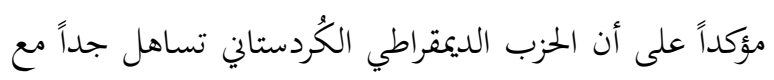

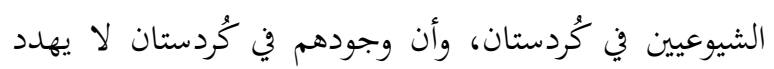
مركز ومكانة الحزب الديمقراطي الكُردستاني (66). ومن جانبها بادرت الحكومة المركزية بإثارة الخلافات

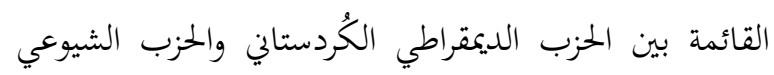

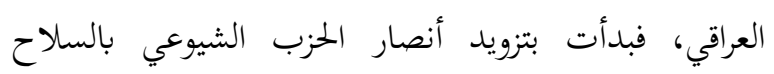

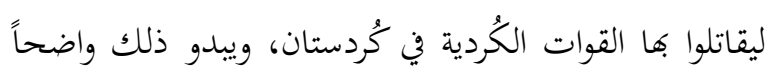

حلول موعد إنتهاء السنوات الأربعة على بيان الحادي عشر

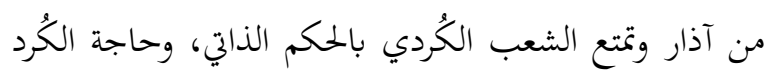

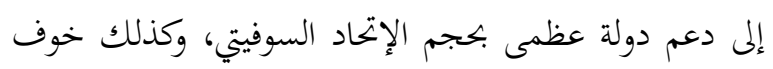
الإتحاد السوفيتي من نشوء صلات بين الثورة الكُردية والولايات المتحدة الأمريكية، والتي كانت أجهزة الإستخبارات السوفيتية (K. G. B.) ب - تدهور العلاقات الكُردية مع الحزب الشيوعي

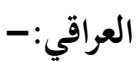
كان التقارب بين العراق والإتحاد السوفيتي يزداد قوة بإطراد، وانفتح النظام في العراق على الإتحاد السوفيتي بشكل

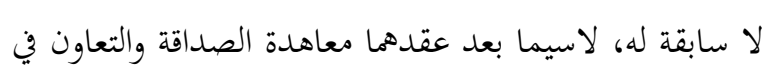
9 نيسان 1972، والتي بمقتضاها تدفقت الأسلحة المتطورة بلا حساب على العراق، ولم يقتصر التعاون العراقي السوفيتي على هذا بل تعداه إلى الحقل السياسي فحثّ الإتحاد السوفيتي

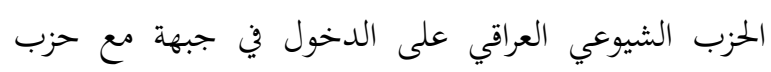
البعث العربي الاشتراكي، وتم ذلك في 17 تموز 1973 1973، وبهذا أفىى الحزب الشيوعي (58) تلك العلاقة التي كانت تربطه

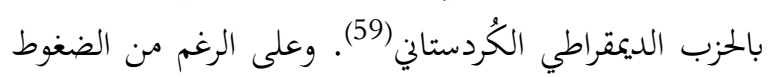

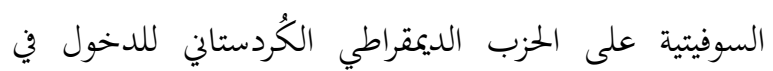
الجبهة الوطنية ، إلا أنه رفض ذلك، مما أدى ذلك إلى فتور

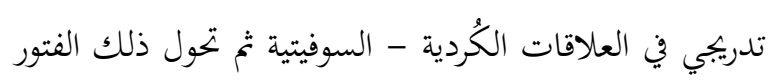

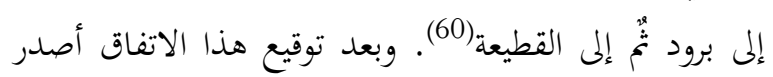

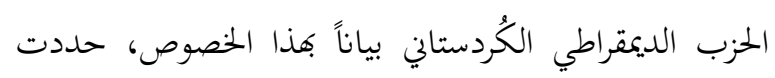

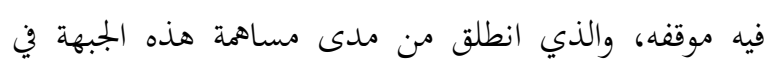

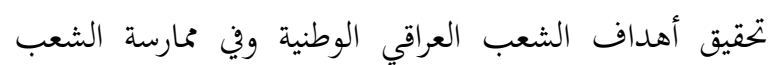
الكُردي لحقه في الحكم الذاتي ضمن الجمهورية العراقية(61).

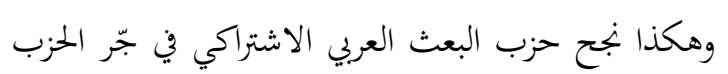

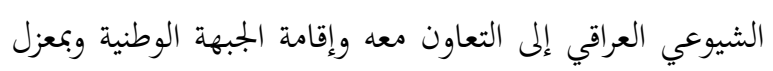

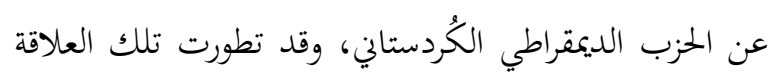

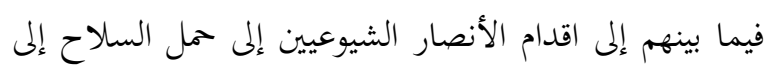

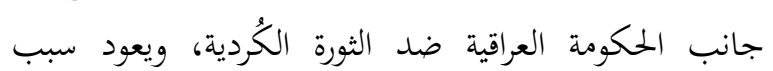
مشاركتهم في هذه العلاقة إلى إنسجام سياستهم مع الإتحاد العداد 
استعرض فيه الجانبان التعاون الأخوي بينهما والقوى الوطنية الأخرى خلال نضالهما الوطني المشترك من أجل تعزيز وصيانة

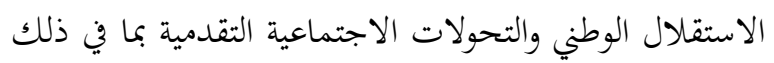

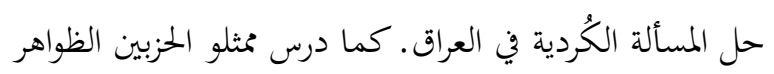

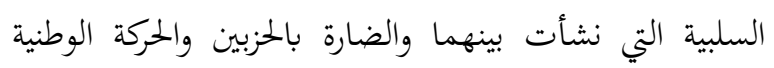

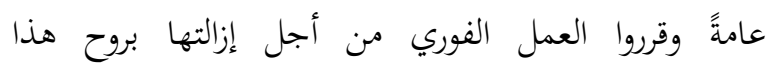

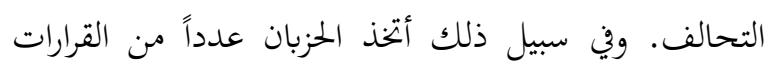

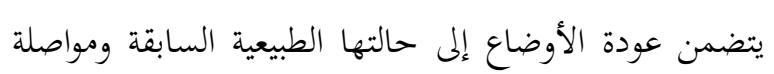

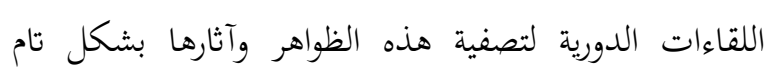

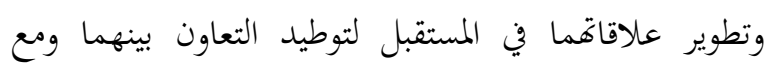

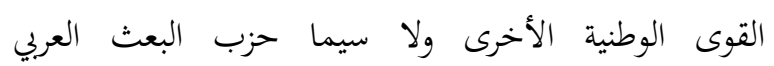
الاشتراكي (71).

على الرغم من عقد الاتفاق بين الحزب الديمقراطي

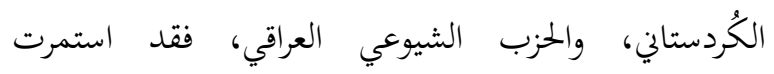

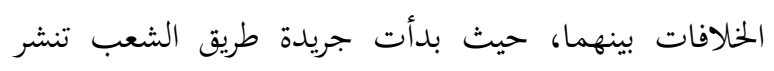

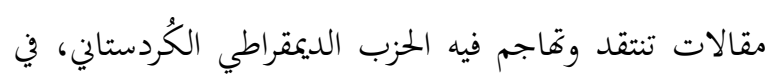

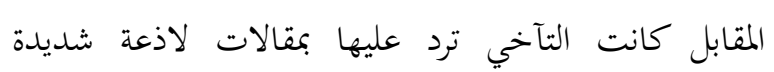

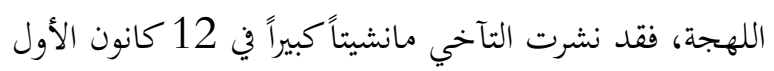
1973 بعنوان:"إيضاح من الحزب الديمقراطي الكُردستاني

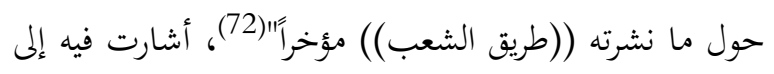

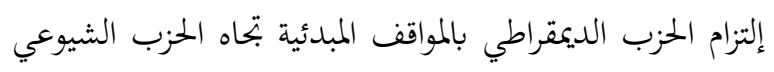

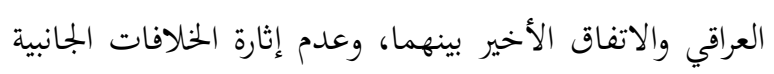

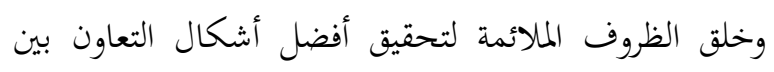

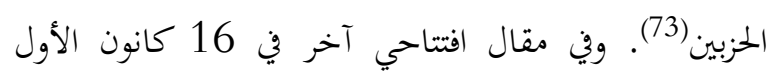

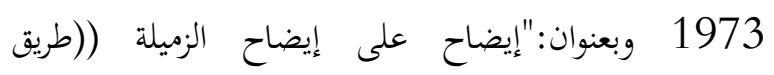

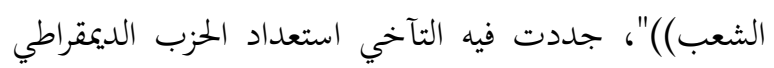

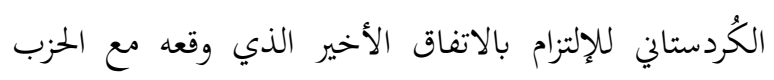
الشيوعي العراقي، والإصرار على تشكيل لجنة مشتركة

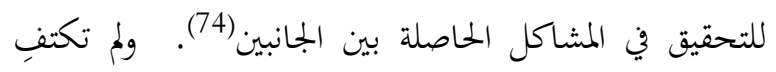

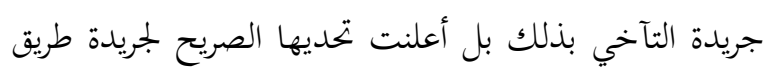
الشعب، ففي مقال لها نشر في 22 كانون الأول 1973

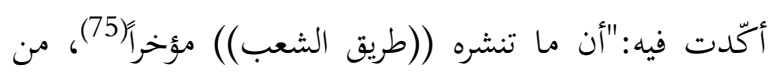

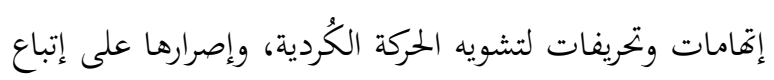

من خلال البرقية التي بعثها الملا مصطفى البارزاني إلى رئيس

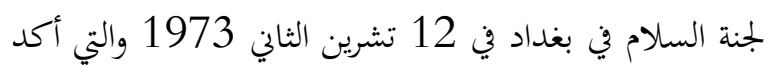

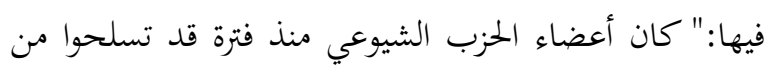

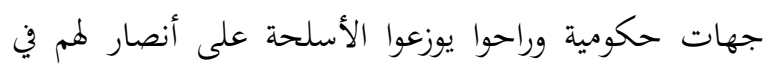

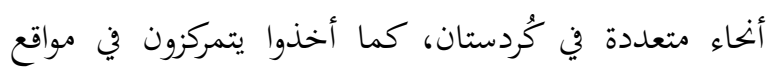

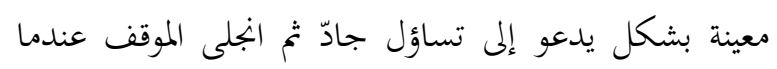

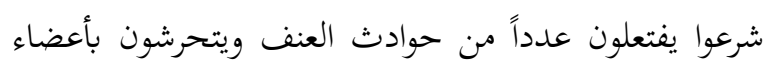

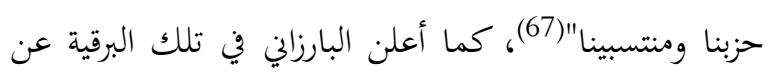
رغبة قيادة الثورة الكُردية في المحافظة على الأمن والاستقرار ووحدة الصف الوطني، والقيام بكل ما ينبغي عمله للوصول إلى تحقيق هذا الهدف، وفي الوقت نفسه طالب البه البارزاني

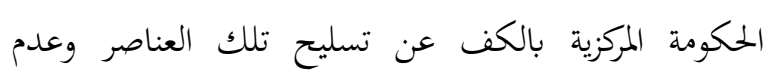

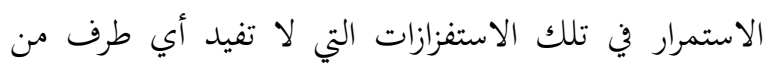
الأطراف الوطنية وتضر في الوقت نفسه مصلحة البلاد

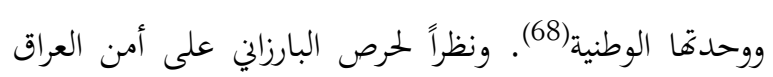

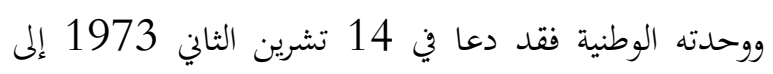

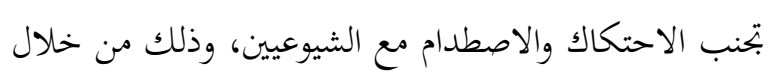

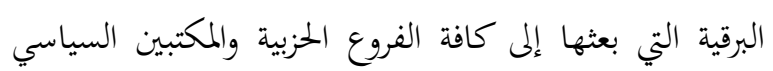
والعسكري للحزب الديمقراطي الكُردستاني (69).

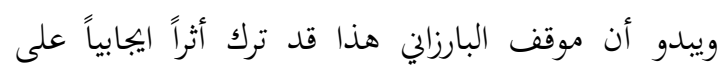

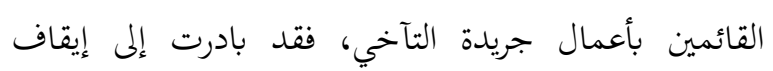

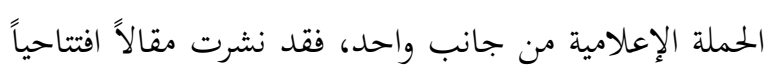

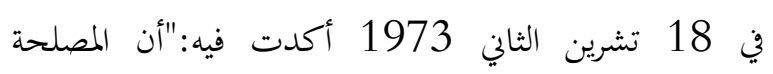

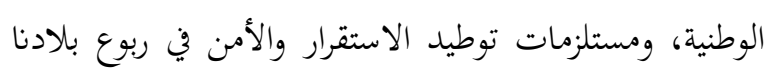

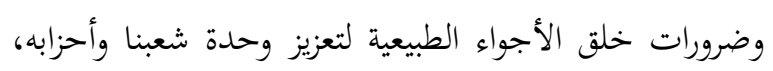

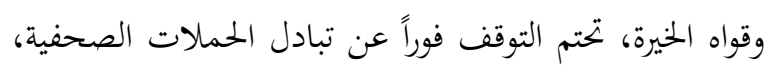

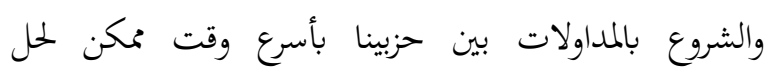
المشاكل المعلقة، وإيجاد السبل، والمناخ الإيجابي لتصفية الآثار

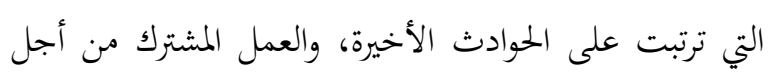

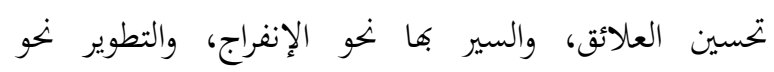

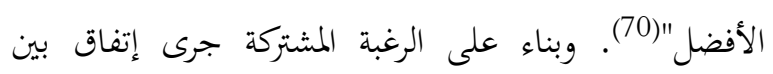

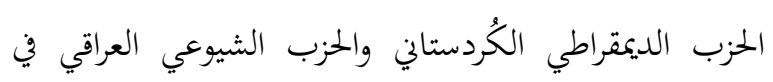
20 تشرين الثاني 1973، وصدر بيان مشترك بين الحزبين 
لاسيما عندما اقترب موعد إعلان الحكم الذاتي المقرر في 11 آذار 1974.

الخاتمة:

يتبين من خلال ما تم عرضه في هذا البحث أهمية موقف

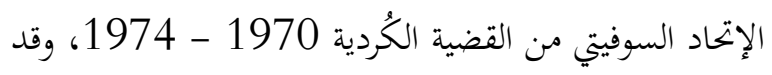

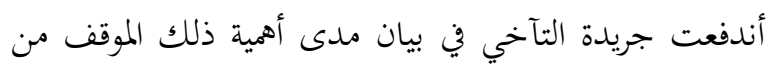

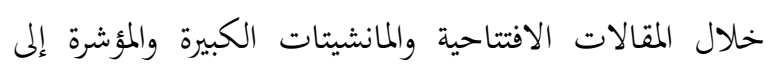

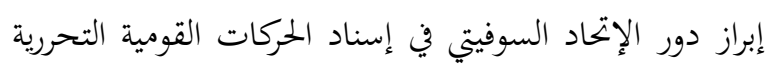

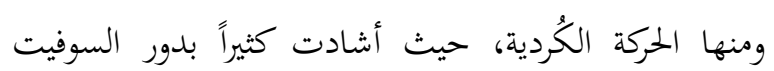
وقادها في تقريب وجهات النظر بين الحكومة العراقية والقيادة

الكُردية والتي توجت بالإعلان عن بيان 11 آذار 1970. عندما توثقت العلاقات العراقية - السوفيتية أيدتا جريدة

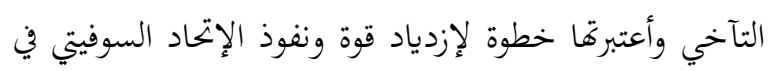

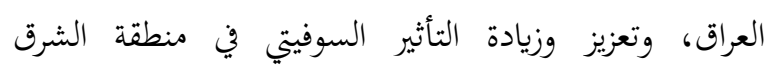

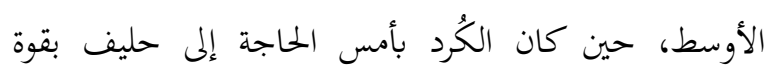
وحجم الإتحاد السوفيتي كقوة عالمية تتبنى القضية الكُردية

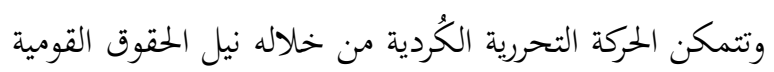

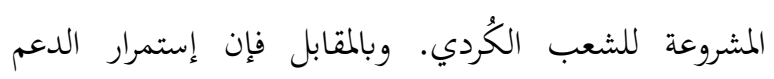

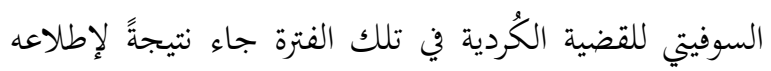

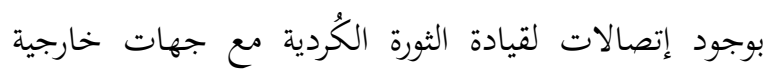

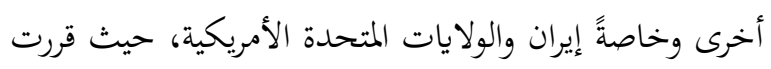

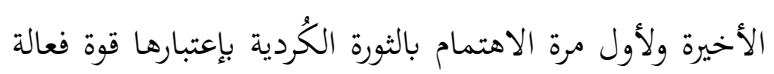
تستطيع الوقوف أمام الحكومة العراقية المتحالفة مع الإتحاد السوفيتي.

كانت للإتحاد السوفيتي مصالحه الخاصة وسياسته التي

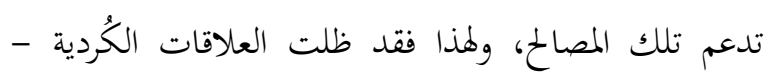

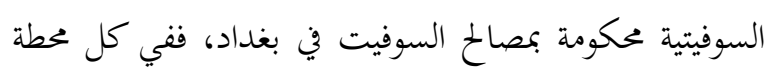

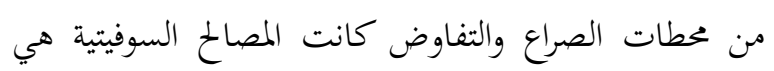

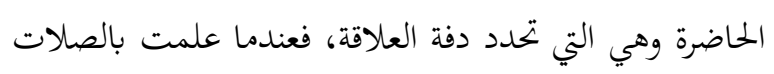

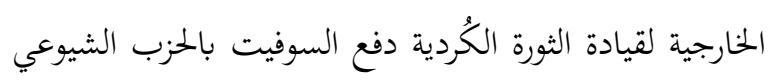

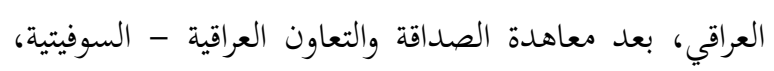
إلى التحالف مع حزب البعث الحاكم آنذاك، ومن ثم إثارة

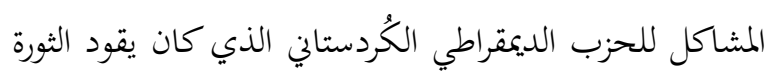

هذا النهج، يأتي تكريساً للمخطط المعادي لتطلعات الشعب

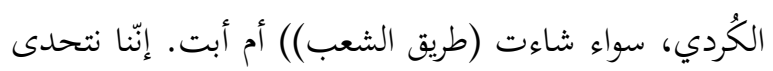

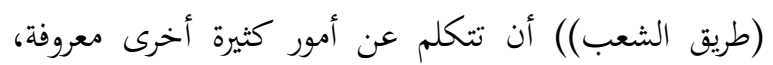
وذلك بنفس الحرية التي تشوه فيها حركة الشعب الكُردي. إنّا

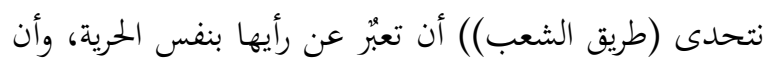

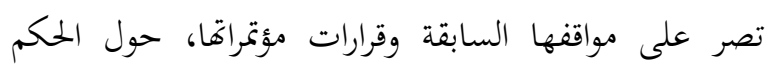
الذاتي للشعب الكُردي"(76). وحول حقيقة وضع الشيوعيين في كُردستان، أشارت التآخي إلى أن الحزب الديمقراطي الكُردستاني أرسل في 10

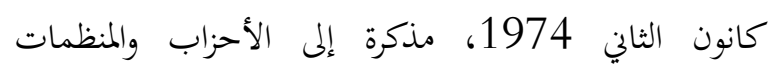

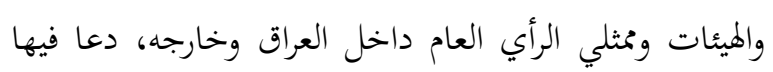

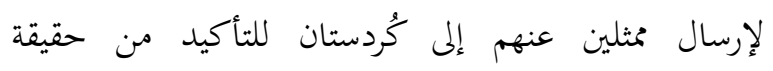
الأوضاع، وتوفير جميع المستلزمات التي يطلبوها لضمان ذلك.

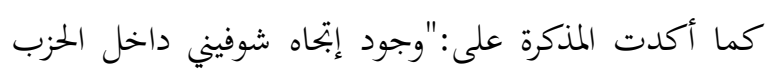
الشيوعي العراقي يعمل على نسف العلاقات الودية التقليدية بينا وبينهم في سبيل الحصول على مغانم آنية وضيقة ... استلموا ألوف القطع من الأسلحة، ولم تفلح جهودنا لإقناعهم

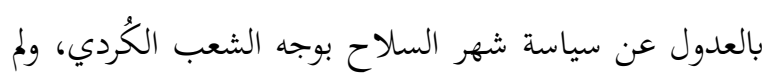

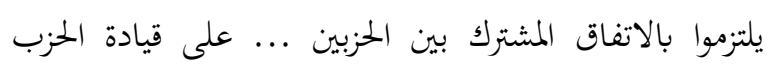

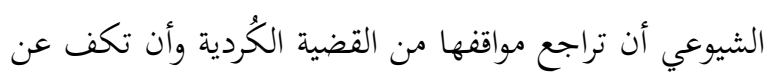

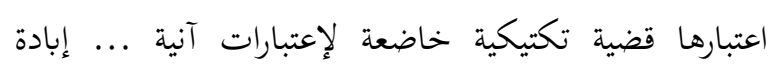
الشيوعيين وتصفيتهم قمم مغرضة وحاقدة، عبثاً يحاول الشيوعيون إلصاقها بحزبنا الذي سيضل ثابتاً في مواقفه المبدئية وعلاقاته الطيبة مع أصدقائه في الداخل والخارج"(77).

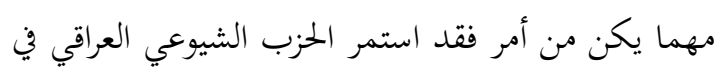

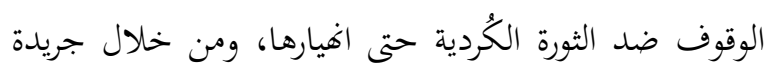

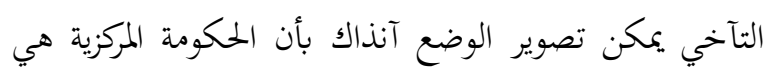
التي كانت تثير المشاكل بين الحزبين الديمقراطي الكُردستاني

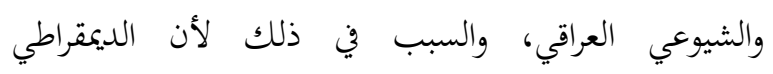

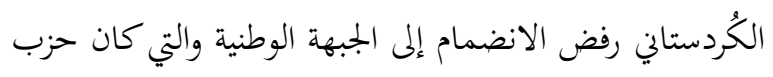

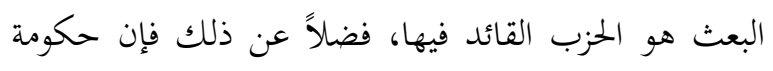

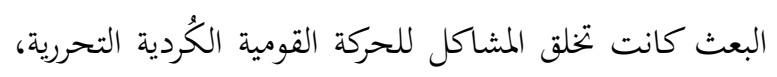


حول السياسة الخارجية. للمزيد ينظر : يفغيني بريماكوف، الشرق الأوسط

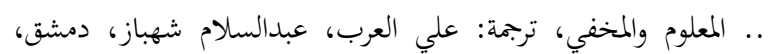
2006، ص ص25.

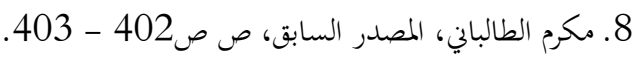

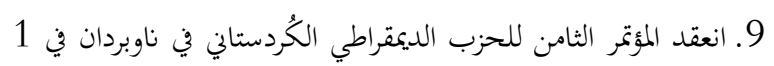
تموز 1970 وحضره 488 مندوباً مثلوا عشرات الألوف من أعضاء الحزب في فروعه وقطاعاته المختلفة. للمزيد عن هذا المؤتمر ينظر : حبيب محمد كريم، تأريخ الحزب الديمقراطي الكوردستاني - العراق (ين مططات

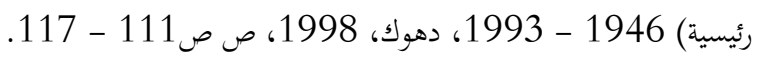

10. مقتبس من: جريدة التآخي، العدد (477)، 2 تموز 1970. 11. جريدة التآخي، العدد (477)، 2 تموز 1970. 12. بعد إندلاع ثورة أيلول (1961 - 1975) 1975 كان الإتحاد السوفيتي يزود الحكومات العراقية بالسلاح والعتاد، وفي الوقت نفسه كان يقدم

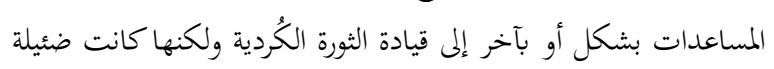
إذا ما قيست بما كانوا يزودون للحكومات العراقية. حيث كان بان هناك تبادل للآراء والمراسلات بين الحكومة السوفيتية وبين قيادة الثورة الكُردية بواسطة وسطاء معتمدين كان يقوم بها أحياناً عزيز شريف أو دارا توفيق أو عن طريق اللقاءات المباشرة، حيث كان مبعوثي القيادة السوفيتية يزورون الملا مصطفى البارزاني في أثناء زياراهم إلى العراق ضمن الوفود

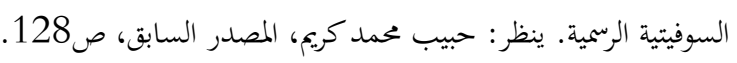

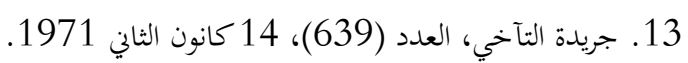

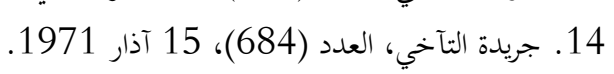

15. جريدة التآخي، العدد (872)، 27 تشرين الأول العدد (18)، 1971.

16. جريدة التآخي، العدد (871)، 26 تشرين الأول 1971 (871)، 1971

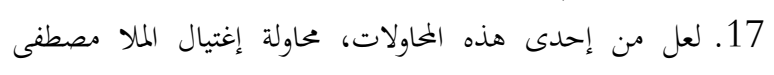
البارزاني في 29 أيلول 1971 في حاجي عمران، والتي جرت باحكام

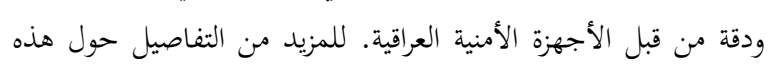

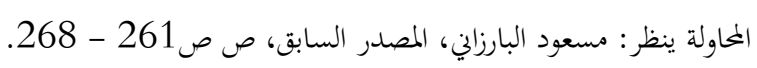

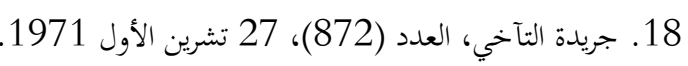

19 . جريدة التآخي، العدد (884)، 10 تشرين الثاني 1971 العدد (2018)، 1920

20. جريدة التآخي، العدد (920)، 25 كانون الأول 1971 (920)، 1981 (920)،

21. جريدة التآخي، العدد (920)، 25 كانون الأول 1971. 22. جريدة التآخي، العدد (988)، 20 (جريدة آذار العدد (920)، 1972. 23. جريدة التآخي، العدد (1003)، 8 نيسان العدد (983)، 1972. 24. ضم الوفد الكُردي أعضاء المكتب السياسي للحزب العدب الديمقراطي

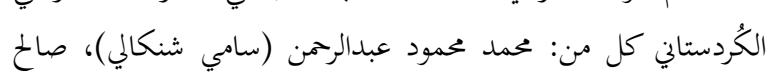
اليوسفي، نوري شاويس، علي عبدالله، وكذلك احسان شيرزاد ودارا توفيق عضوا اللجنة المركزية للحزب. ينظر: جريدة التآخي، العدد (1004)، 9 نيسان 1972 (100)
الكُردية، وبهذا الشكل تمكن الإتحاد السوفيتي من استخدام الحزب الشيوعي العراقي بالشكل الذي ينسجم مع سياسته العامة.

وعلى الرغم من الآثار السلبية للدعم السوفيتي للقضية

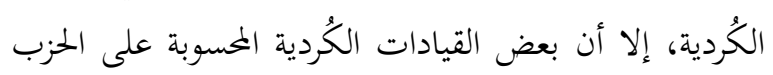

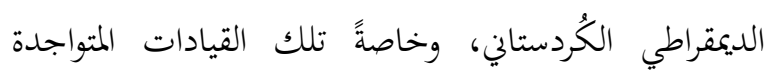
آنذاك في بغداد، مثل صالح اليوسفي، عضو المكتب السياسي للحزب، ودارا توفيق، عضو اللجنة المركزية للحزب ورئيس بل تحرير جريدة التآخي، كانوا دائماً ما يدعون الملا مصطفى البارزائ إلى عدم قطع علاقات الثورة الكُردية مع الإتحاد السوفيتي، ويبدو ذلك واضحاً من خلال اللقاءات والزيارات التي كانت تتم بين تلك القيادات الكُردية وبين المسؤولين السوفيت سواء في بغداد أو في موسكو، والتي أشارت التآخي إلى تفاصيها، حيث كانوا على ثقة تامة بأن الإتحاد السوفيتي هو الحليف الأقوى للقضية الكُردية. الهوامش: 1. ميهفان محمد حسن رشيد البامرني، سياسة الإتحاد السوفيتي بتحاه الحركة القومية الكوردية التحررية في كوردستان الجنوبية (1945 -

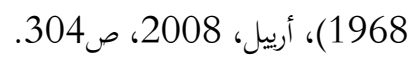
2. ماريون فاروق سلوغلت، بيتر سلوغلت، من الثورة إلى الدكتاتورية

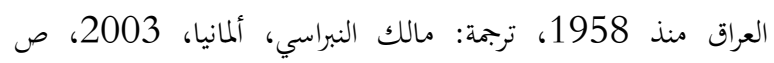
ص ص ص 171 - 173 3. مكرم الطالباني، مراحل الحركة القومية الكُردية، السليمانية، 2009، ص ص ص صن2 - 403 - 403. 4. ميهفان محمد حسن رشيد البامري، المصدر السابق، ص305. 5. صبرية جرجيس عبدالرحمن ئيمينكي، جريدة التآخي دراسة في موقفها مبانيا

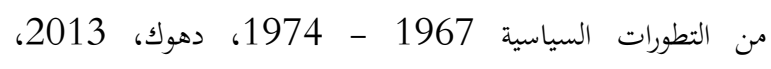

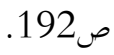
6. للمزيد من التفاصيل عن هذا البيان ينظر: مسعود البارزاني، البارزاني

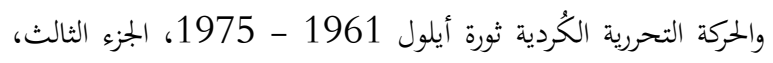

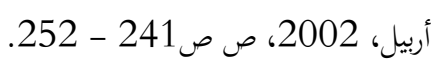
7. انظم بريماكوف للحزب الشيوعي السوفيتي عام 1959، صلح وعمل

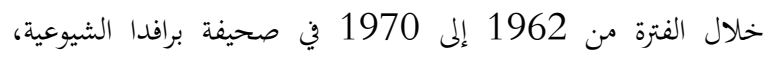
مراسالًا لشؤون الشرق الأوسط، حيث أصبح يتحدث اللغة العربية

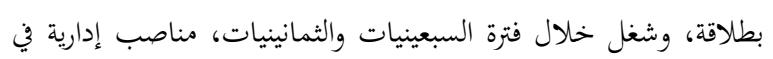

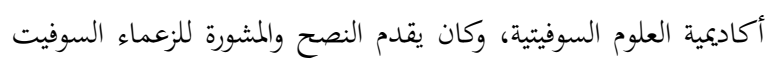


51.نشرت جريدة التآخي مقالاً إفتتاحيا بعنوان:"تحية للذكرى السادسة والخمسين لثورة أكتوبر الاشتراكية العظمى"، أعربت فيها عن إعجابها وشكرها لتلك الثورة وقادما. ينظر: العدد (1480)، 7 تشرين الثاني 1973

52. جريدة التآخي، العدد (1288)، 19 (1283وز 1973. 53. جريدة التآخي، العدد (1467)، 23 تشرين الأول 1973.

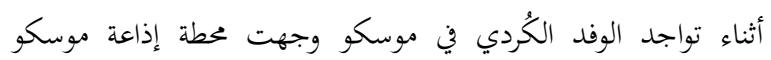
باللغتين العربية ومحطة إذاعة جمهورية أرمينيا السوفيتية، القسم الكُردي،

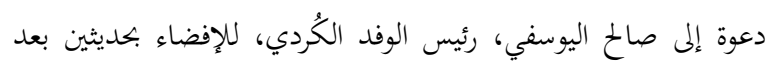

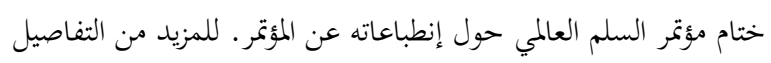
ينظر: جريدة التآخي، العدد (1497)، 27 تشرين الثاني 1973

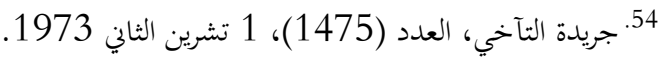
55. جريدة التآخي، العدد (1489)، 18 تشريدة التآي، الثاني (1973)، 1973؛ العدد

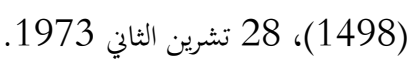

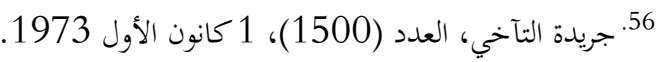

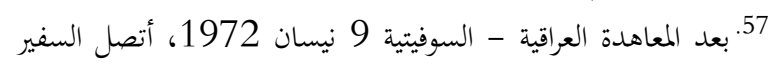
الأمريكي في طهران بالقيادة الكُردية في مايس 1972 وزار معقل الثورة الكُردية في حاجي عمران وإلتقى بالملا مصطفى البارزاني، وذكر بأن

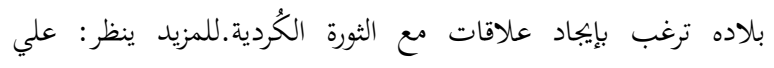
سنجاري، صفحات من نبع ذاكرتي في الحزب الديمقراطي الكوردستاني،

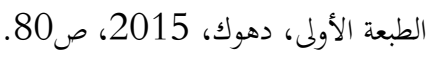

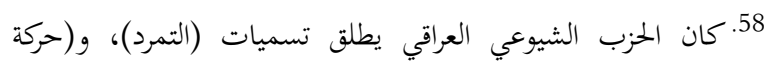
القوميين الأكراد اليائسة) وغيرها من التسميات المماثلة، على الثورة الكُردية طوال عامي 1961 و 1962. إلا أن (حركة القوميين الأكراد اليائسة) قد تحولت، في نظر الحزب الشيوعي إلى الثورة الكُردية العادلة بعد إنقلاب شباط 1963. وكان الشيوعيون في كُردسان، خلال الفترة عقب الإنقلاب المذكور، يقولون أن كل آمالهم وأمنياتم هي أن يشتركوا في القتال من أجل الثورة، وأن يستشهدوا من أجل الحكم الذاتي، وأن يقبلوا في صفوف الثورة الكُردية، بأية صورة كانت. وفي عام 1970 تعرض الحزب الشيوعي العراقي إلى حملة إضطهاد من قبل الحكومة

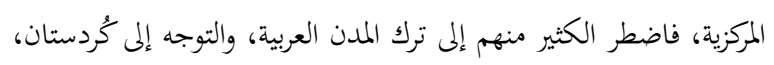

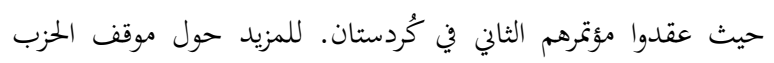

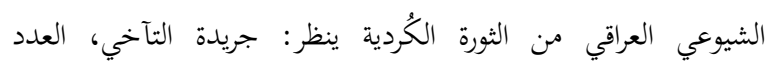
(1484)، 12 تشرين الثاني 1973. 59. مسعود البارزاني، المصدر السابق، ص ص281، 281 - 283.

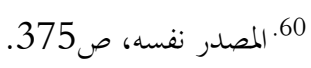

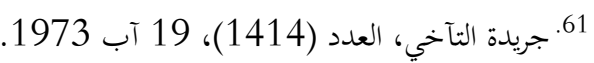

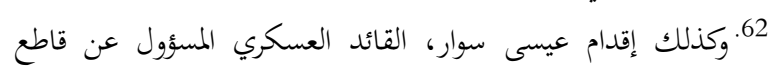

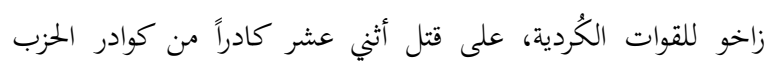

25. جريدة التآخي، العدد (1004)، 9 نيسان 1972.

26. جريدة التآخي، العدد (1002)، 6 نيسان 1972.

27. جريدة التآخي، العدد (1004)، 9 نيسان العدد (1002)، 1972.

28. جريدة التآخي، العدد (1009)، 15 نيسان العدد (10)، 1972 نيسان 1972.

29. جريدة التآخي، العدد (506)، 8 آب 1970)، 1970؛ العدد (510)، نيسان (510)،

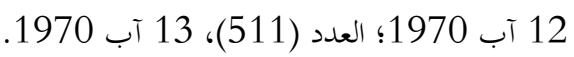

30. جريدة التآخي، العدد (705)، 10 (705)، نيسان 1971 (685)، 1913.

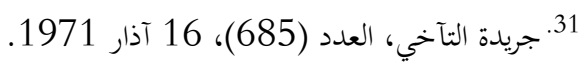

32. جريدة التآخي، العدد (685)، 16 آذار 1971.

33. جريدة التآخي، العدد (705)، 10 (705 نيسان العدد (J8)، 1971.

34. جريدة التآخي، العدد (963)، 19 شباط العدد (J5) 1972.

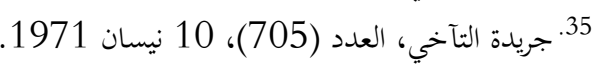

36. جريدة التآخي، العدد (963)، جريدة 19 شباط العدد (1972)، 1972.

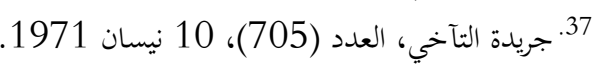

38. جريدة التآخي، العدد (1004)، 9 نيسان 1972.

39. حول بنود تلك المعاهدة ينظر: جريدة التآخي، العدد (1005)، العلد (10)، نيدان

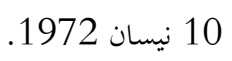

40. جريدة التآخي، العدد (1007)، 12 نيسان 1972 نيسان 1972.

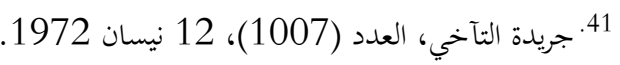

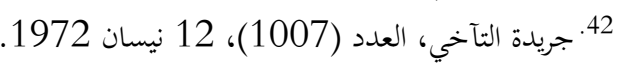

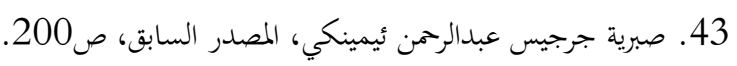

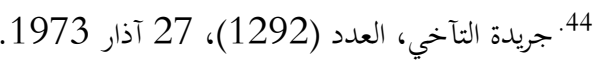

45. جريدة التآخي، العدد (1303)، 9 نيسان 1973 (1203)، 1973

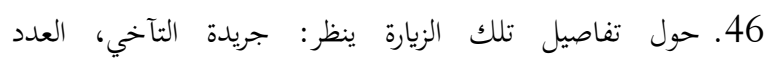

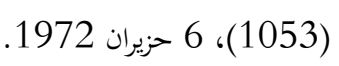
47. جريدة التآخي، العدد (1283)، (1283 15 آذار 1973. 48. في 7 نيسان 1947 تأسس هذا الحزب تحت اسم (حزب البعث البث العدان العربي)، وقد كان من مؤسسيه: ميشيل عفلق، وصلاح البيطار، وجلال

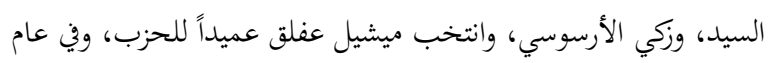
1952 دمج حزب البعث العربي بالحزب الاشتراكي بقيادة أكرم

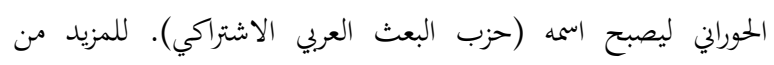

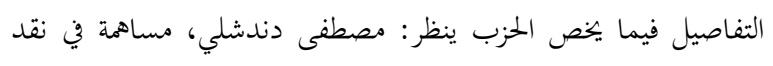
الحركات السياسية في الوطن العربي: حزب البعث العزب العربي الاشتراكي

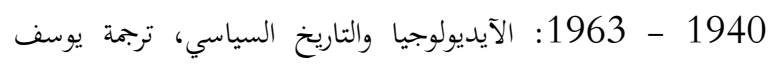
جباعي، مصطفى دندشلي، د. م، 1979. 49. جريدة التآخي، العدد (1283)، 15 (آذار 1973. 50.جريدة التآخي، العدد (1286)، 19 آذار 1973 1973؛ العدد (1289)، (19) 24 آذار 1973. 
72.نشرت (طريق الشعب) في ثلاثة أعداد وتحت عناوين:"تزايد القلق

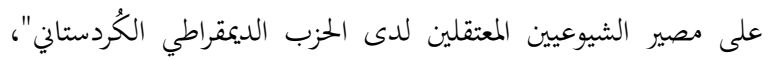

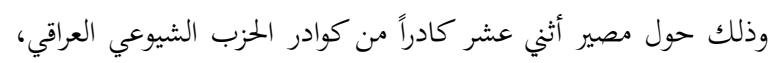
إقمت فيه الحزب الديمقراطي الكُردستاني باختطافهم وإخفاء مصيرهم.

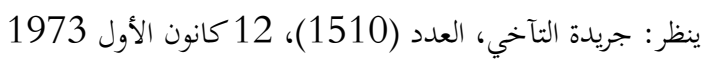

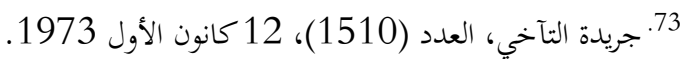

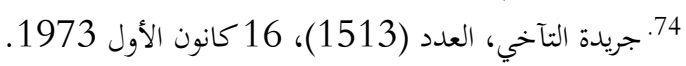

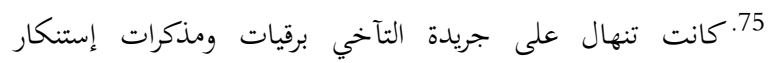

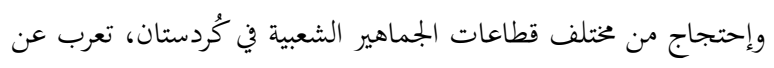

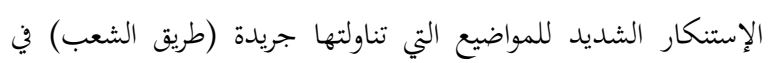

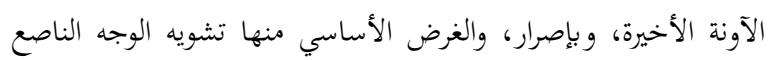

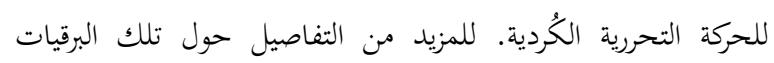

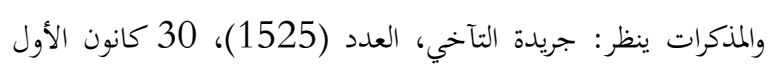

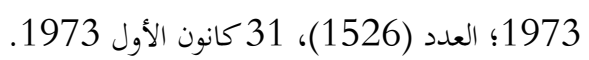

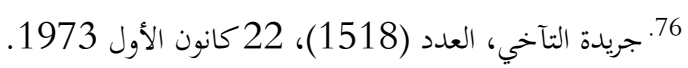
حول نص تلك المذكرة ينظر: جريدة التآخي، العدد (1536)، 1518)، 14

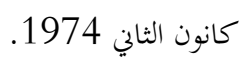

الشيوعي العراقي الذين كانوا قادمين من سوريا دون وجه حق وعدم

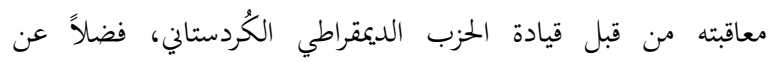

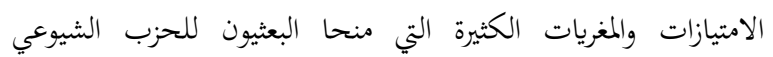

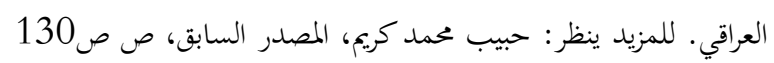
131 63.جريدة التآخي، العدد (1484)، 12 تشرين الثاني 1973؛ مسعود البارزاني، المصدر السابق، ص283.

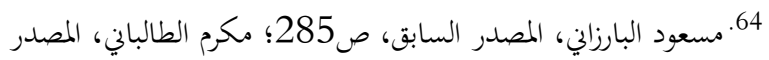

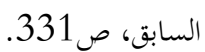
65. جريدة التآخي، العدد (1486)، 1487، 14 تشرين الثاني 1973؛ العداند (1487)، 15 تشرين الثاني (1485)، (1483، 1973.

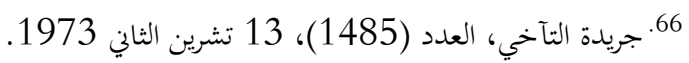
67. جريدة التآخي، العدد (1486)، 1486، 1485)، 14 تشرين الثانيان 14 تشرين الثان 1973.

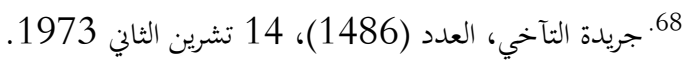

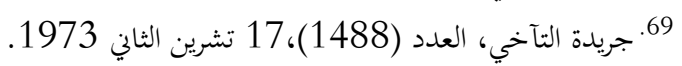

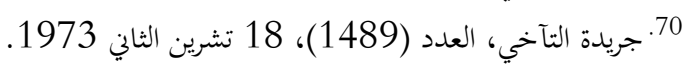
71. جريدة التآخي، العدد (1492)، 141، 1489)، 18 تشرين الثرين الثاني 1973؛ 1973؛ وحول نص البيان ينظر: العدد (1493)، 22 تشرين الثاني 1492، تشرين الثان 1973. 


\title{
هلويستى يُّكَتيا سوفيّيَى بهرامبهر برسا كوردى 1970 - 1974 ل ميانا روزناما (التآخي)
}

\begin{abstract}
كورتيا ليَكولينيّ:

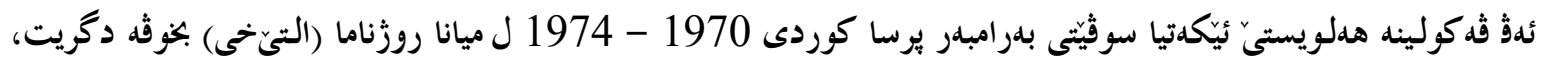

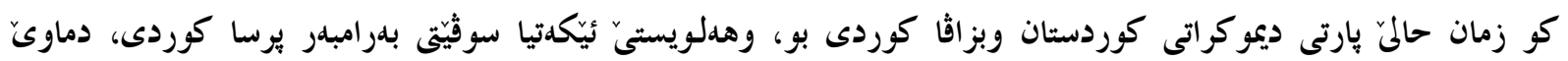

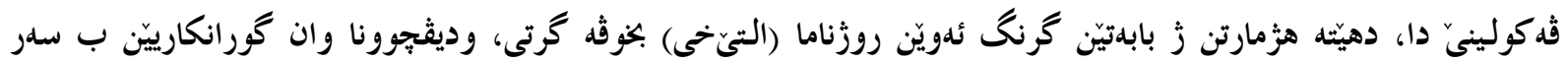

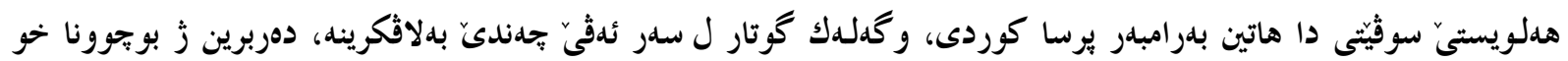

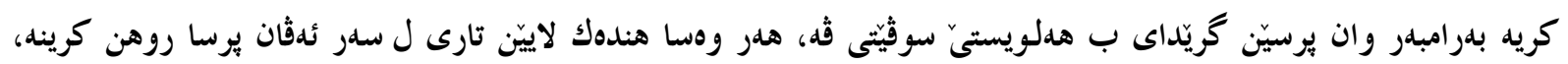

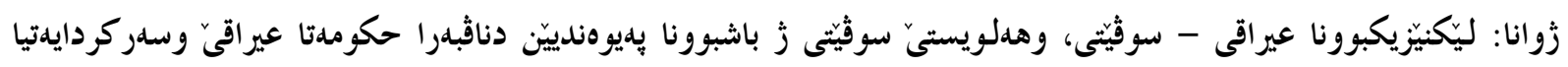

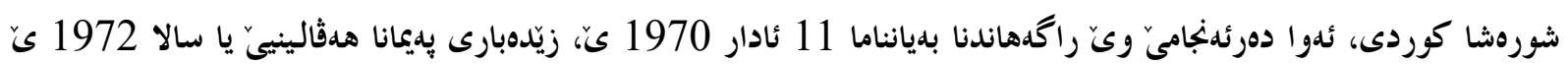

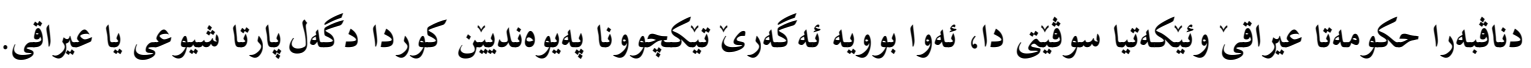

\section{The Soviet Union position on the Kurdish Issue 1974 - 1970 In the light of Al Takhi Newspaper}

\begin{abstract}
:
This study deals with the Soviet Union position on the Kurdish issue (1970 - 1974) in the light of Al Takhi Newspaper, the mouthpiece of the Kurdish Democratic Party and the Kurdish movement at that time. The Soviet position on the Kurdish issue, during the period of the research, is one of the important topics addressed by Al Takhi newspaper. It has followed the developments in the Soviet position on the Kurdish issue, and published many articles expressing its opinion on that. Al Takhi Newspaper has revealed some ambiguities in these issues such as the convergence between Iraq and the Soviet Union, the Soviet position on the improvement of relations between the Iraqi government and the leadership of Kurdish movement, which resulted in statement of 11 March, 1970 agreement, as well as the Treaty of friendship between the Iraqi government and the Soviet Union in 1972, which eventually led to the deterioration of relations between the Kurds and the Iraqi Communist party.
\end{abstract}

